\title{
RESEARCH
}

Open Access

\section{Secondary prevention of Alzheimer's dementia: neuroimaging contributions}

\author{
Mara ten Kate ${ }^{1,2^{*} \dagger} \mathbb{D}$, Silvia Ingala ${ }^{1 \dagger}$, Adam J. Schwarz ${ }^{3,4}$, Nick C. Fox ${ }^{5}$, Gaël Chételat ${ }^{6}$, Bart N. M. van Berckel ${ }^{1}$, \\ Michael Ewers ${ }^{7}$, Christopher Foley ${ }^{8}$, Juan Domingo Gispert ${ }^{9}$, Derek Hill ${ }^{10}$, Michael C. Irizarry ${ }^{4}$, \\ Adriaan A. Lammertsma', José Luis Molinuevo ${ }^{9}$, Craig Ritchie ${ }^{11}$, Philip Scheltens ${ }^{2}$, Mark E. Schmidt ${ }^{12}$, \\ Pieter Jelle Visser ${ }^{2}$, Adam Waldman ${ }^{11}$, Joanna Wardlaw ${ }^{11,13}$, Sven Haller ${ }^{14}$ and Frederik Barkhof ${ }^{1,15}$
}

\begin{abstract}
Background: In Alzheimer's disease (AD), pathological changes may arise up to 20 years before the onset of dementia. This pre-dementia window provides a unique opportunity for secondary prevention. However, exposing non-demented subjects to putative therapies requires reliable biomarkers for subject selection, stratification, and monitoring of treatment. Neuroimaging allows the detection of early pathological changes, and longitudinal imaging can assess the effect of interventions on markers of molecular pathology and rates of neurodegeneration. This is of particular importance in pre-dementia AD trials, where clinical outcomes have a limited ability to detect treatment effects within the typical time frame of a clinical trial. We review available evidence for the use of neuroimaging in clinical trials in pre-dementia AD. We appraise currently available imaging markers for subject selection, stratification, outcome measures, and safety in the context of such populations.
\end{abstract}

Main body: Amyloid positron emission tomography (PET) is a validated in-vivo marker of fibrillar amyloid plaques. It is appropriate for inclusion in trials targeting the amyloid pathway, as well as to monitor treatment target engagement. Amyloid PET, however, has limited ability to stage the disease and does not perform well as a prognostic marker within the time frame of a pre-dementia AD trial. Structural magnetic resonance imaging (MRI), providing markers of neurodegeneration, can improve the identification of subjects at risk of imminent decline and hence play a role in subject inclusion. Atrophy rates (either hippocampal or whole brain), which can be reliably derived from structural MRI, are useful in tracking disease progression and have the potential to serve as outcome measures. MRI can also be used to assess comorbid vascular pathology and define homogeneous groups for inclusion or for subject stratification. Finally, MRI also plays an important role in trial safety monitoring, particularly the identification of amyloid-related imaging abnormalities (ARIA). Tau PET to measure neurofibrillary tangle burden is currently under development. Evidence to support the use of advanced MRI markers such as resting-state functional MRI, arterial spin labelling, and diffusion tensor imaging in pre-dementia AD is preliminary and requires further validation.

Conclusion: We propose a strategy for longitudinal imaging to track early signs of $A D$ including quantitative amyloid PET and yearly multiparametric MRI.

Keywords: Alzheimer's disease, Neuroimaging, Secondary prevention, Clinical trials

\footnotetext{
*Correspondence: m.tenkate1@vumc.nl

${ }^{\dagger}$ Mara ten Kate and Silvia Ingala contributed equally to this work.

'Department of Radiology and Nuclear Medicine, Neuroscience Campus

Amsterdam, VU University Medical Center, Amsterdam, the Netherlands

${ }^{2}$ Alzheimer Center \& Department of Neurology, Neuroscience Campus

Amsterdam, VU University Medical Center, PO Box 7056, 1007 MB

Amsterdam, the Netherlands

Full list of author information is available at the end of the article
}

(c) The Author(s). 2018 Open Access This article is distributed under the terms of the Creative Commons Attribution 4.0 International License (http://creativecommons.org/licenses/by/4.0/), which permits unrestricted use, distribution, and reproduction in any medium, provided you give appropriate credit to the original author(s) and the source, provide a link to the Creative Commons license, and indicate if changes were made. The Creative Commons Public Domain Dedication waiver (http://creativecommons.org/publicdomain/zero/1.0/) applies to the data made available in this article, unless otherwise stated. 


\section{Background}

Alzheimer's disease (AD) is the leading cause of dementia worldwide and it is pathologically characterised by the deposition of extracellular $\beta$-amyloid plaques and intracellular neurofibrillary tangles of hyperphosphorylated tau proteins [1]. Pathological changes may start up to 20 years before the onset of symptoms [2-5]. To date, treatments have only been approved for the dementia stage of the disease and provide modest symptomatic benefit but no slowing of progression. A global research priority is to find therapies to prevent or delay symptom onset and functional decline [6], and a number of candidate agents have shown promise in cell or animal models. Despite this, clinical trials of potential disease-modifying treatments have proven unsuccessful thus far. This may be partly due to limitations of the treatments (e.g. incorrect molecular target or inadequate target engagement, dose, or duration). However, the failures could also reflect inappropriate trial populations. Typically, trials have recruited patients with mild to moderate dementia in whom the disease process may be too advanced to be amenable to treatment. An alternative approach is to treat subjects at risk of $\mathrm{AD}$ dementia, which is the aim of secondary prevention-preventing neurodegeneration, cognitive decline, and dementia [7, 8].

Research criteria from the International Working Group (IWG) [9, 10] and the National Institute on Ageing-Alzheimer Association (NIA-AA) [11-13] propose the use of biomarkers to define pre-clinical AD as the disease stage characterised by amyloid pathology, with or without neurofibrillary tangles and/or features of neurodegeneration, even in the absence of clinical manifestations. Mild cognitive impairment (MCI) is used to denote an intermediate stage between normal cognition and dementia in which subjects have objective cognitive impairment in the absence of functional disability interfering with daily activities. MCI with biomarker evidence of $\mathrm{AD}$ has been termed prodromal $\mathrm{AD}$ under the IWG criteria $[9,10]$ and MCI due to AD by the NIA-AA in 2011 [12], but the 2018 research framework does not take into account syndromic diagnosis [11]. Non-demented subjects with evidence of amyloid pathology, i.e. subjects with AD without dementia [14], provide an opportunity for intervention prior to irreversible neuronal loss. Designing trials for subjects in pre-dementia stages of $\mathrm{AD}$ is greatly facilitated by the ability to identify subjects at increased risk of cognitive decline and progression to dementia. In the earliest stage, neuropsychological testing to detect subtle cognitive abnormalities in the absence of obvious symptoms has some predictive value [15], but biomarkers that are sensitive to underlying pathological change could further increase prognostic accuracy. Ideally, early-stage biomarkers should predict risk and likely timing of cognitive decline and progression to dementia in a reliable, non-invasive, and cost-effective manner. Secondly, trials in non-demented subjects would benefit from biomarkers that can monitor treatment effects and should thus reflect disease progression, be sensitive to detect pathologically significant changes over time and in response to treatment, and be highly reproducible and reliable in a multi-centre setting. Neuroimaging techniques have developed rapidly over the past decade and they currently offer a comprehensive armamentarium that can be employed to address this unmet need. Over and above structural neuroimaging markers that are widely available and used to support AD diagnosis at the dementia stage, advances in imaging techniques allow the detection and quantification of molecular, functional, and structural brain changes that precede gross atrophy.

In this paper, we discuss the use of neuroimaging markers in subject selection for inclusion or stratification in secondary prevention trials, their potential to serve as outcome markers in trials, and for monitoring trial safety. The overall aim is to devise a neuroimaging strategy that will maximise the information required to enrol and monitor secondary prevention trials in $\mathrm{AD}$ (including progression from $\mathrm{MCI}$ to dementia). To identify potential imaging markers, a comprehensive review of the existing literature was performed. Based on the evidence from the literature and the personal experience of the authors, recommendations are centred around three domains: 1) imaging markers for subject selection and stratification; 2) imaging markers with potential to be used as outcome measures in clinical trials; and 3) imaging markers for monitoring trial safety. The utility of longitudinal imaging as a run-in for clinical trials, identification of exclusion criteria, and vascular comorbidity were also taken into account.

\section{Methods}

\section{Neuroimaging modalities: from molecular changes to structural damage}

The past two decades have seen major advances in neuroimaging. Different imaging modalities are now able to track different aspects of the hypothesised pathological cascade of events in $\mathrm{AD}$ in vivo [3] (Box 1, Figs. 1, and 2). Positron emission tomography (PET) with amyloid-specific tracers, and more recently also tau-binding ligands, can visualise and quantify molecular pathology at an early stage. Alterations in functional imaging biomarkers, reflecting early synaptic dysfunction and neuronal injury, can be measured with various PET and magnetic resonance imaging (MRI) measures. Collectively, molecular and functional changes may lead to synaptic loss, inflammation, white matter damage, and neuronal cell death, eventually leading to macroscopic changes such as regional and global brain atrophy seen on structural MRI. Increasing evidence demonstrates that cerebrovascular changes have an additive effect on neurodegeneration, accelerate cognitive decline and 


\section{Box 1: Neuroimaging armamentarium \\ Molecular markers \\ Amyloid PET is a reliable in-vivo marker of $\beta$-amyloid plaque load. The first amyloid-specific tracer, ${ }^{11} \mathrm{C}$ Pittsburgh compound B (PiB), was developed in 2004 and binds with high affinity to fibrillary amyloid [200]. With the introduction of ${ }^{18} \mathrm{~F}$-labelled amyloid tracers (florbetapir, florbetaben, flutemetamol) which obviate the need for on-site cyclotron and radiochemistry facilities, amyloid PET has become more widely available [201]. Recently developed tau PET tracers have entered clinical testing and might be used as a measure of tau pathology [51]. Tau PET imaging recapitulates Braak stages in vivo, making tau PET a possible measure of neurofibrillary pathology spread [54, 202]. \\ Functional markers \\ PET imaging with ${ }^{18} \mathrm{~F}$-fluorodeoxyglucose (FDG-PET) measures cerebral glucose metabolism and is used in clinical practice for the (differential) diagnosis of neurodegenerative disorders. Patients with AD typically show hypo-metabolism in the posterior cingulate and temporo-parietal cortices [56]. Arterial spin labelling (ASL) is a non-invasive MRI technique for quantification of cerebral blood flow. Cerebral blood flow is coupled to brain metabolism, and reduced blood flow patterns may overlap with those of glucose hypo-metabolism [60, 64]. Resting state functional MRI (rs-fMRI) measures spontaneous brain function by examining inter- regional coupling of low-frequency temporal oscillations in the blood oxygenation level-dependent (BOLD) signal. Intrinsic brain networks in AD mainly show decreased functional connectivity in the default mode network [70]. \\ Structural markers \\ Medial temporal atrophy visualised on MRI is the most established imaging marker for $\mathrm{AD}$ at the dementia and $\mathrm{MCl}$ stages [203]. Using T1-weighted MRI, volumetric measures of structures such as the hippocampus and entorhinal cortex can be reliably obtained by automated segmentation. With higher resolution proton density or T2 MRI, hippocampal subfields can be delineated to further specify the location of atrophy [90]. Diffusion tensor imaging (DTI) detects the diffusion of water molecules in neural tissue reflecting white matter integrity [204]. In subjects with AD, DTI abnormalities can be detected in the posterior regions, limbic structures, and corpus callosum [106, 107].}

progression to dementia, and may even be part of the pathological cascade of $\mathrm{AD}$ [16-18]; hence, we also address MRI markers of vascular pathology.

\section{Search strategy and selection criteria}

References for this review were identified by searching the PubMed/Medline database in August 2017. Relevant articles were identified using the following search terms alone and in varying combinations: "amyloid PET", "tau PET", "MRI", "structural MRI", "functional MRI", "FDG PET", "fluorodeoxyglucose PET", "TSPO PET", "diffusion tensor imaging", "arterial spin labeling", "magnetic resonance spectroscopy", "cognitively healthy", "normal cognition", "mild cognitive impairment", "subjective cognitive decline", "Alzheimer's disease". Papers published in English were included. Further references were obtained by screening references from retrieved articles and on the basis of the personal knowledge of the authors. In the case of topics already extensively covered in the literature, as was often the case for MCI, a reference article or review was selected by the authors. The final selection of articles was based on relevance to the topics covered in this review, as judged by the authors

\section{Subject selection and stratification}

Various planned and ongoing clinical trials for $\mathrm{AD}$ primarily target the amyloid cascade, aiming at the removal of amyloid plaques or prevention of misfolding of amyloid into the $\beta$ conformation [19]. We recommend that trials targeting the amyloid pathway should include methods to recruit subjects with evidence of an appropriate level of amyloid pathology. Various PET tracers are capable of measuring and spatially localising $\beta$-amyloid deposits. Alternatively, $\beta$-amyloid peptides may be measured in cerebrospinal fluid (CSF). Studies have demonstrated good concordance between CSF $\beta$-amyloid 1-42 and amyloid PET measures, even though these markers might represent different pools of amyloid in the brain [20]. Several studies suggest that CSF $\beta$-amyloid levels become abnormal prior to an amyloid PET signal [2123], making CSF markers more sensitive for the selection of subjects in the earliest phases of amyloid accumulation.

The quantification of amyloid pathology with PET or in CSF for screening purposes in non-demented subjects is expensive, invasive, and likely inefficient. Therefore, a step-wise approach to subject inclusion is proposed (Fig. 3). Using demographic, genetic, and other clinical data, subjects may be screened for increased risk of amyloid pathology. In a recent study, the positive predictive value to detect amyloid-positive subjects at the pre-clinical stage, based on a combination of demographic information, apolipoprotein E (APOE) $\varepsilon 4$ genotype, and neuropsychological changes over 24 months, was 0.65 , which was $60 \%$ higher than the prevalence of amyloid in the cohort [24]. Moreover, plasma assays for $\beta$-amyloid have been recently developed, with preliminary evidence suggesting high performance in predicting cerebral amyloid burden $[25,26]$. The potential scalability of this method, its cost-benefit ratio, and the minimal invasiveness make it a very promising tool in clinical trials, which could be incorporated early in the screening process. After screening for an increased probability of amyloid positivity, subjects may first undergo 

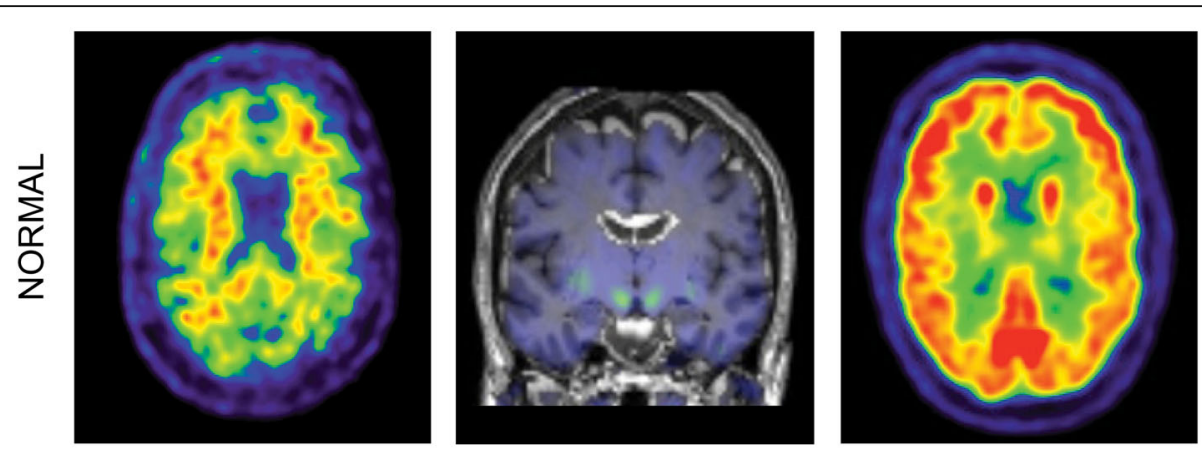

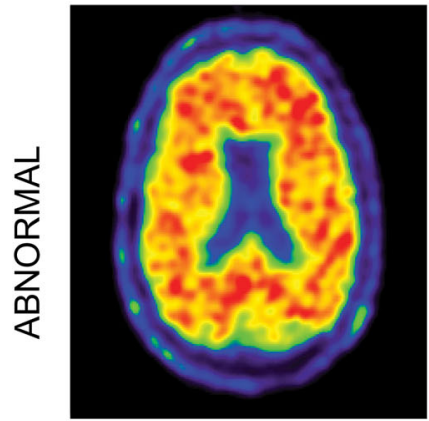

AMYLOID PET

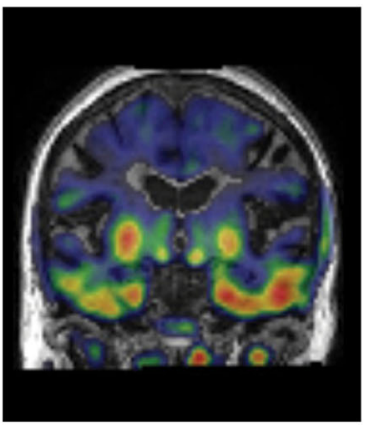

TAU PET

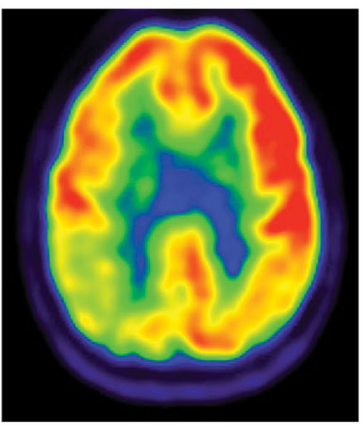

FDG PET

Fig. 1 PET imaging biomarkers. Examples of normal (top) and abnormal (bottom) positron emission tomography (PET) imaging markers in three different subjects. For all images, the warmer the colour, the more tracer binding. Left: amyloid PET with [ $\left.{ }^{18} \mathrm{~F}\right]$-flutemetamol. In the abnormal scan, diffuse tracer binding to fibrillary amyloid can be observed. Middle: tau PET with $\left[^{18} \mathrm{~F}\right]$-AV-1451. In the abnormal scan, tracer binding to tau can be observed in the temporal lobes. Right: Fluorodeoxyglucose (FDG)-PET scan. In the abnormal scan, there is hypometabolism of the parietal lobes
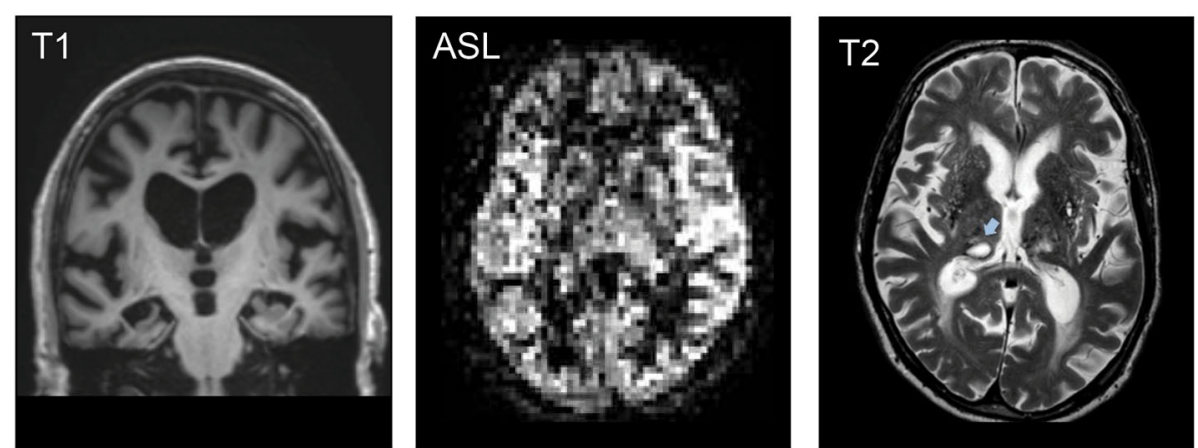

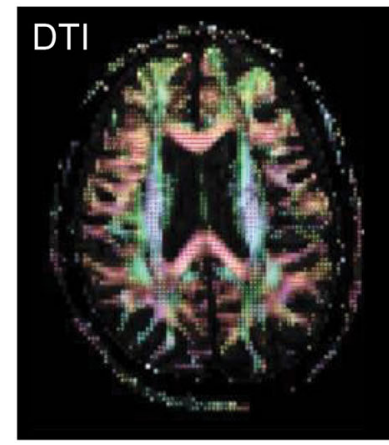

STRUCTURAL

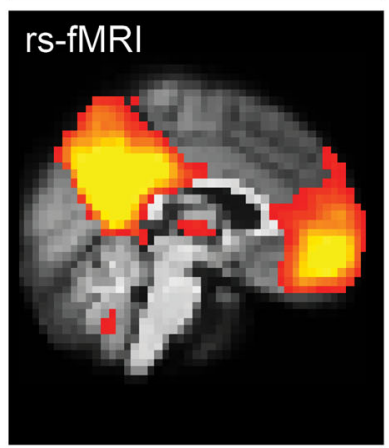

FUNCTIONAL

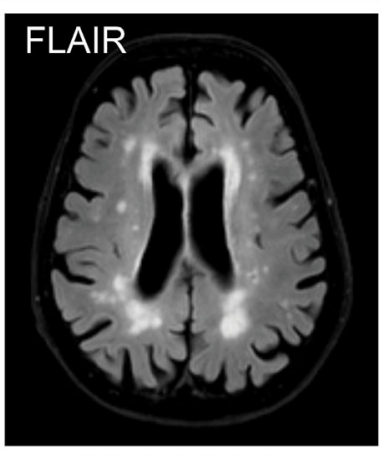

VASCULAR

Fig. 2 MRI imaging biomarkers. Left: T1-weighted MRI (top) showing severe hippocampal atrophy and example of diffusion tensor imaging (DTI) (bottom). Middle: example of functional imaging markers with arterial spin labelling (ASL) (top) and resting state functional magnetic resonance imaging (rs-fMRI) (bottom). Right: imaging of vascular pathology with thalamus lacune on T2 (top; arrow) and white matter hyper-intensities on fluid attenuated inversion recovery (FLAIR) (bottom) 


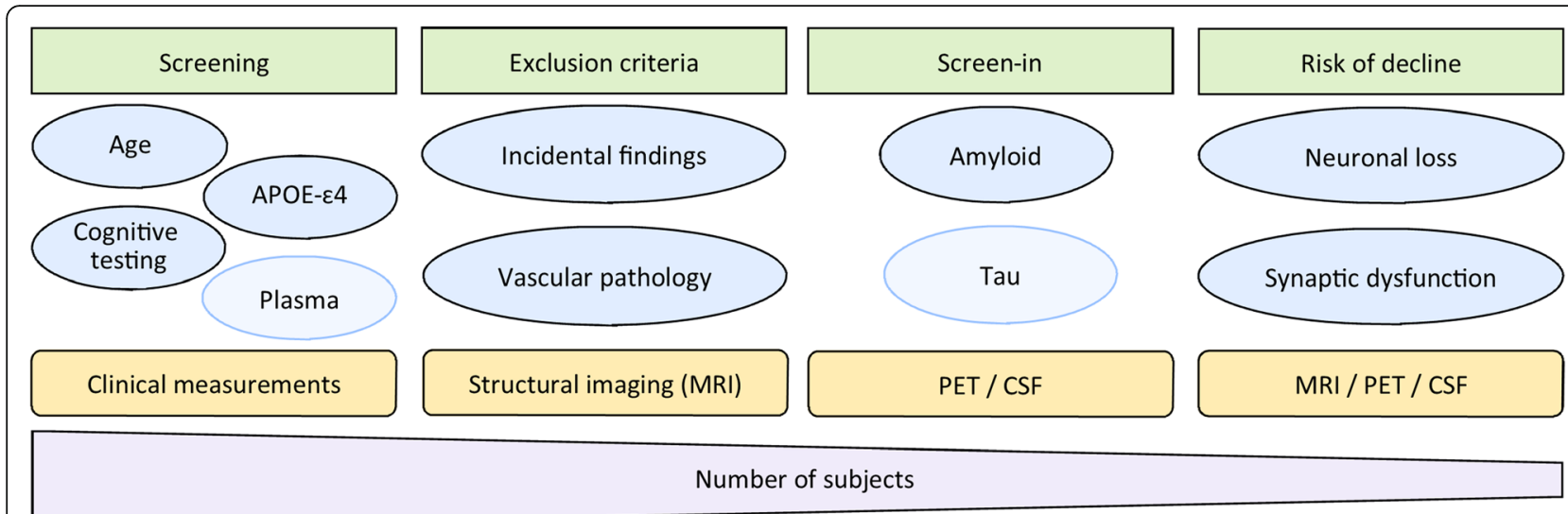

Fig. 3 Step-wise approach for subject inclusion and testing. Information from clinical measurements (and, in the near future, possibly also plasma) may be used to select subjects with an increased risk of amyloid pathology (screening). Provided there are no exclusion criteria, molecular measurements of amyloid (or tau, depending on the treatment target) can be used to screen-in subjects for clinical trials. Finally, imaging measures predicting imminent cognitive decline may be used for additionally enrichment. APOE apolipoprotein E, CSF cerebrospinal fluid, MRI magnetic resonance imaging, PET positron emission tomography

structural MRI which, combined with clinical information, can be used to exclude subjects with incidental findings that might interfere with the assessment of clinical outcomes or with a high likelihood of having or developing neurodegenerative diseases other than $\mathrm{AD}$ (Additional file 1: Table S1). Imaging changes associated with other neurodegenerative disorders are, however, unlikely to be present in the early stages, which may preclude the reliable exclusion of these subjects.
Structural and functional imaging markers can also be used to identify subjects at risk of imminent cognitive decline, which will be reviewed in the following paragraphs. This is especially relevant for phase 3 trials in subjects with pre-clinical $\mathrm{AD}$ targeting cognition as a primary outcome. Enrichment of clinical trials targeting clinical end-points by means of amyloid PET and/or MRI may reduce sample sizes and costs, as shown in subjects with MCI $[27,28]$, but this work needs to be extended to the pre-clinical phase. Table 1

Table 1 Summary of evidence for use of imaging markers for subject selection and as outcome measures in clinical trials in pre-dementia Alzheimer's disease

\begin{tabular}{|c|c|c|c|c|c|c|c|}
\hline & $\begin{array}{l}\text { Imaging } \\
\text { technique }\end{array}$ & $\begin{array}{l}\text { Pathological } \\
\text { specificity for } \\
\text { Alzheimer's disease }\end{array}$ & $\begin{array}{l}\text { Prediction of progression } \\
\text { in cognitively normal }\end{array}$ & $\begin{array}{l}\text { Prediction of } \\
\text { progression } \\
\text { in } \mathrm{MCl}\end{array}$ & Reproducibility & $\begin{array}{l}\text { Sensitivity } \\
\text { to change }\end{array}$ & $\begin{array}{l}\text { Response } \\
\text { to treatment }\end{array}$ \\
\hline \multirow[t]{2}{*}{ Molecular } & Amyloid PET & Strong & Moderate & Strong & Good & Moderate & Established \\
\hline & Tau PET & $\begin{array}{l}\text { Preliminary evidence } \\
\text { with promising } \\
\text { results }\end{array}$ & Unknown & Unknown & $\begin{array}{l}\text { Preliminary } \\
\text { evidence }\end{array}$ & Unknown & Unknown \\
\hline \multirow[t]{3}{*}{ Functional } & ASL & Moderate & Weak & Weak & Moderate & $\begin{array}{l}\text { Preliminary } \\
\text { evidence }\end{array}$ & $\begin{array}{l}\text { Preliminary evidence } \\
\text { for exercise } \\
\text { intervention }\end{array}$ \\
\hline & rs-fMRI & Moderate & Unknown & Weak & Moderate & $\begin{array}{l}\text { Preliminary } \\
\text { evidence }\end{array}$ & $\begin{array}{l}\text { Preliminary evidence } \\
\text { for symptomatic } \\
\text { drugs }\end{array}$ \\
\hline & FDG-PET & Moderate & Moderate/good & Strong & Good & Good & $\begin{array}{l}\text { Established for } \\
\text { symptomatic drugs }\end{array}$ \\
\hline \multirow[t]{3}{*}{ Structural } & $\begin{array}{l}\text { T1: } \\
\text { Hippocampal } \\
\text { volume }\end{array}$ & Moderate & $\begin{array}{l}\text { Good; although long } \\
\text { follow-up is needed }\end{array}$ & Strong & Good & Good & $\begin{array}{l}\text { Established, although } \\
\text { few effective studies }\end{array}$ \\
\hline & $\begin{array}{l}\text { T1: Cortical } \\
\text { atrophy }\end{array}$ & Moderate & $\begin{array}{l}\text { Moderate/good depending } \\
\text { on regions; long follow-up } \\
\text { is needed }\end{array}$ & Good & Good & Good & Unknown \\
\hline & DTI & Moderate & Weak & Moderate & Moderate & Unknown & Unknown \\
\hline
\end{tabular}


summarises the available evidence for the use of different imaging markers for subject selection in clinical trials.

\section{Molecular imaging \\ Amyloid PET: predictor of decline?}

Amyloid pathology measured with PET is an established prognostic marker in subjects with MCI (sensitivity $82 \%$ (95\% confidence interval (CI) 74-88) and specificity $56 \%$ (95\% CI 49-64) to distinguish stable MCI patients from those who progress to dementia) [29]. In cognitively normal subjects, amyloid positivity has been associated with an increased risk of cognitive decline and progression to dementia in several longitudinal studies [30-41], although studies with sufficiently long follow-up and large sets of data to establish the exact risk are required [40-43] (Table 2). The method of choice to classify subjects as amyloid-positive or amyloid-negative remains a matter of debate (Box 2). Recent evidence has also suggested that amyloid plaques might follow consistent deposition patterns in different regions of the brain, making it possible to stage amyloid pathology [44]. Although the relationship between amyloid positivity and later cognitive decline in cognitively normal subjects has been established, it has been suggested that the rate at which this occurs depends on the presence of neurodegeneration [45, 46]. Amyloid positivity is also consistently associated with increased brain atrophy rates in cognitively normal subjects (Additional file 1: Table S2). Hence, amyloid pathology is a necessary factor to assess whether an individual will decline due to AD pathology but is not sufficient to stage disease, or to predict when and how

Table 2 Prediction of cognitive decline using amyloid PET in cognitively normal subjects

\begin{tabular}{|c|c|c|c|c|c|c|}
\hline \multirow[t]{2}{*}{ Reference } & \multicolumn{4}{|l|}{ Study design } & \multirow[t]{2}{*}{ Tracer } & \multirow[t]{2}{*}{ Main outcome } \\
\hline & Cohort & Size & Follow-up & Mean age & & \\
\hline $\begin{array}{l}\text { Donohue } \\
\text { et al., } \\
2017 \text { [40] }\end{array}$ & ADNI & $N=445$ & $\begin{array}{l}\text { Median } \\
3.1 \text { years }\end{array}$ & 74 & $\begin{array}{l}\text { Various tracers } \\
\text { or CSF }\end{array}$ & $\begin{array}{l}\text { A } \beta+\text { : worse mean scores after } 4 \text { years on Preclinical } \\
\text { Alzheimer Cognitive Composite score, } \\
\text { MMSE and CDR-SB. }\end{array}$ \\
\hline $\begin{array}{l}\text { Petersen } \\
\text { et al., } \\
2016[39]\end{array}$ & $\begin{array}{l}\text { Mayo Clinic Study } \\
\text { of Aging }\end{array}$ & $N=564$ & $\begin{array}{l}\text { Median } \\
2.5 \text { years }\end{array}$ & 78 & $\mathrm{PiB}$ & $\begin{array}{l}\mathrm{A} \beta+\text { : increased rate of cognitive decline in various } \\
\text { cognitive domains and progression to } \mathrm{MCl} \text {. }\end{array}$ \\
\hline $\begin{array}{l}\text { Vemuri et al., } \\
2015 \text { [38] }\end{array}$ & $\begin{array}{l}\text { Mayo Clinic Study } \\
\text { of Aging }\end{array}$ & $N=393$ & $\begin{array}{l}\text { Mean } \\
2.7 \text { years }\end{array}$ & 78 & $\mathrm{PiB}$ & $\begin{array}{l}A \beta+\text { : increased rate of cognitive decline compared } \\
\text { to } A \beta-\text {. }\end{array}$ \\
\hline $\begin{array}{l}\text { Lim et al., } \\
2012 \text { [34] }\end{array}$ & $\mathrm{AIBL}$ & $N=141$ & 18 months & 76 & $\mathrm{PiB}$ & $\begin{array}{l}\text { A } \beta+\text { : greater cognitive decline on working memory } \\
\text { and verbal and visual episodic memory. }\end{array}$ \\
\hline $\begin{array}{l}\text { Lim et al., } \\
2014[35,73]\end{array}$ & $\mathrm{AIBL}$ & $N=320$ & 36 months & 70 & Various tracers & $\begin{array}{l}\text { A } \beta+: \text { greater cognitive decline on verbal and visual } \\
\text { episodic memory. }\end{array}$ \\
\hline $\begin{array}{l}\text { Rowe et al., } \\
2013 \text { [41] }\end{array}$ & $\mathrm{AIBL}$ & $N=183$ & 36 months & 72 & $\mathrm{PiB}$ & $\begin{array}{l}\mathrm{A} \beta+\text { : predictor of progression to } \mathrm{MCl} / \text { dementia (OR } \\
\text { 4.8). }\end{array}$ \\
\hline $\begin{array}{l}\text { Kawas et al., } \\
2013 \text { [36] }\end{array}$ & $90+$ study & $N=13$ & $\begin{array}{l}\text { Median } \\
1.5 \text { years }\end{array}$ & 94 & Florbetapir & $\begin{array}{l}\text { A } \beta+\text { : steeper declines on most cognitive tests, } \\
\text { particularly global cognitive measures. }\end{array}$ \\
\hline $\begin{array}{l}\text { Doraiswamy } \\
\text { et al., } \\
2014 \text { [37] }\end{array}$ & $\begin{array}{l}\text { AV45-A11 study. } \\
\text { Multi-site, USA }\end{array}$ & $N=69$ & 36 months & 70 & Florbetapir & $\begin{array}{l}\text { A } \beta+\text { : greater decline on ADAS-Cog, digit-symbol- } \\
\text { substitution test, verbal fluency test and CDR-SB. }\end{array}$ \\
\hline $\begin{array}{l}\text { Villemagne } \\
\text { et al., } \\
2011[147]\end{array}$ & $\begin{array}{l}\text { Austin Health Memory } \\
\text { Disorder Clinic and } \\
\text { Melbourne Aging Study }\end{array}$ & $N=32$ & $\begin{array}{l}\text { Mean } \\
20 \text { months }\end{array}$ & 73 & $\mathrm{PiB}$ & $\begin{array}{l}\mathrm{A} \beta \text { high: } 16 \% \text { conversion rate to } \mathrm{MCl} \text { by } 20 \text { months } \\
\mathrm{A} \beta \text { high: } 25 \% \text { conversion rate to } \mathrm{MCl} \text { by } 3 \text { years } \\
\mathrm{A} \beta \text { low: } 1 \text { subject developed } \mathrm{MCl}\end{array}$ \\
\hline $\begin{array}{l}\text { Storandt } \\
\text { et al., } \\
2009[31]\end{array}$ & $\begin{array}{l}\text { Washington University } \\
\text { ADRC }\end{array}$ & $N=135$ & $\begin{array}{l}\text { Up to } 19 \text { years. } \\
\text { pre-PET }\end{array}$ & 75 & $\mathrm{PiB}$ & $\begin{array}{l}\text { Increased cognitive decline in episodic and working } \\
\text { memory in amyloid positive subjects (cognition } \\
\text { measured before PET scan). }\end{array}$ \\
\hline $\begin{array}{l}\text { Morris et al., } \\
2009[30]\end{array}$ & Washington University & $N=159$ & Mean 2.4 years & 71.5 & $\mathrm{PiB}$ & $\begin{array}{l}\text { Higher mean cortical binding potential values } \\
\text { predicted progression to AD (HR 4.85, 1.22-19.01). }\end{array}$ \\
\hline $\begin{array}{l}\text { Mormino } \\
\text { et al., } \\
2014[46]\end{array}$ & $\begin{array}{l}\text { Harvard Aging Brain } \\
\text { Study }\end{array}$ & $N=166$ & $\begin{array}{l}\text { Median } \\
2.1 \text { years }\end{array}$ & 74 & $\mathrm{PiB}$ & $\begin{array}{l}\text { Cognitive decline over time was observed only in } \\
\text { cognitively healthy individuals who were } A \beta+\text { and } \\
\text { had evidence of neurodegeneration. }\end{array}$ \\
\hline $\begin{array}{l}\text { Resnick } \\
\text { et al., } \\
2010 \text { [32] }\end{array}$ & $\begin{array}{l}\text { Baltimore Longitudinal } \\
\text { Study of Aging }\end{array}$ & $N=57$ & Mean 10.8 years & 78.7 & $\mathrm{PiB}$ & $\begin{array}{l}\text { A } \beta \text { high: greater decline in mental status and verbal } \\
\text { learning and memory, but not visual memory. } \\
\text { Significant associations in frontal and lateral } \\
\text { temporal regions. }\end{array}$ \\
\hline
\end{tabular}




\begin{abstract}
Box 2: cut-offs for imaging biomarker abnormality
Subject selection on the basis of imaging markers requires the definition of criteria for inclusion. These may involve visual reads and/or pre-defined thresholds for quantitative measures to classify markers as either normal or abnormal. In clinical practice, some imaging markers are commonly interpreted by visual inspection (e.g. atrophy on MRI or amyloid PET), but (semi-)quantitative methods have been suggested to provide more sensitive readouts [5]. The definition of cut-off scores for quantitative imaging markers remains a topic of active research and is dependent on the type of marker, the acquisition method, its intended use, and the relative requirement to maximise sensitivity or specificity [205, 206]. A frequently applied strategy for quantitative markers involves taking the 10th or 90th percentile (depending on the imaging biomarker) of either a normal reference population or an $\mathrm{AD}$ dementia cohort. Alternatively, thresholds may be based on an optimal separation of cognitively normal subjects from dementia patients [206].

In recent studies on ageing, lower thresholds for amyloid pathology than those used to separate cognitively normal from $\mathrm{AD}$ dementia patients have been proposed $[5,41]$. While screening subjects for inclusion in clinical trials, it might be beneficial to also identify subjects with sub-threshold amyloid deposition, as many might have progressed to supra-threshold levels and be in the phase of rapid amyloid accumulation by the time an intervention study commences $[4,140]$. This would allow the best window of opportunity for secondary prevention. It may be valuable to stratify sub-populations based on their amyloid burden into those clearly negative for amyloid pathology, sub-threshold amyloid pathology, and clearly abnormal amyloid burden, rather than dichotomise them into negative/positive categories. It has been suggested that staging of amyloid pathology might be possible, but further investigation is required to assess the feasibility of this [44].
\end{abstract}

fast the decline will occur, since the timing depends on the rate of neurodegeneration [41, 46-48].

\section{Tau PET: novel biomarker of neurofibrillary pathology}

The deposition of neurofibrillary tangles of hyper-phosphorylated and aggregated tau proteins presents with an anatomical distribution mirroring that of neuronal loss and is more closely related in time and magnitude to clinical symptoms than amyloid pathology [3, 49, 50]. Tau PET tracers have been recently developed, and while clinical validation remains limited to date [51] the field is rapidly evolving. The development of tau tracers has been challenging given the intracellular localisation of tau, the relatively low concentrations, and multiple isoforms [51, 52]. The first tau tracers have off-target binding in the basal ganglia and choroid plexus [52]. More recently developed tracers might offer better technical characteristics, including the absence of intra-parenchymal off-target binding in these regions [53].

Since neurofibrillary tangles are more closely related to the onset of symptoms than amyloid, tau PET might be used in the future to identify subjects who are at elevated risk of imminent clinical decline. There are not yet any published prospective longitudinal studies on the predictive value of tau PET on cognitive decline, but it is expected that this area will evolve quickly in the next few years. One study has shown that increased tau-tracer binding in the entorhinal and hippocampal regions was associated with a worse prior longitudinal decline in global cognition and episodic memory measures [54]. Another study showed that, in the cognitively normal elderly, high amyloid and neocortical tau measured with PET was associated with posterior cingulate hypometabolism, which is turn was associated with future cognitive decline [55]. Tau PET may also be valuable as an inclusion criterion (screen-in) or as a means to segregate participants (e.g. on the basis of tau load or degree of spread) or as an outcome measure (prevention of tau spread or signal increase), especially for trials specifically targeting tau pathology.

\section{Functional imaging}

Altered brain glucose metabolism: fluorodeoxyglucose-PET

Patients with AD dementia show characteristic patterns of glucose hypometabolism measured with fluorodeoxyglucose (FDG)-PET, which are also predictive of progression to dementia in subjects with MCI $[29,56,57]$. Moreover, FDG-PET demonstrates a high negative predictive value for progression to $\mathrm{AD}$ dementia in subjects with MCI [57]. In cognitively normal subjects, baseline lateral temporo-parietal and posterior cingulate-precuneus hypometabolism can predict clinical progression to $\mathrm{MCI}$ or dementia with accuracies in the range of $70-80 \%[58,59]$. Hence, FDG-PET has some potential to be used as a marker for trial inclusion or stratification, although changes in cognitively normal subjects are very subtle and thresholds for abnormality are not established.

\section{Reduced cerebral blood flow: arterial spin labelling}

Arterial spin labelling (ASL) can detect changes in cerebral blood flow in patients with MCI and AD dementia $[60,61]$. Only two studies have investigated the predictive value of ASL measures on clinical progression. In subjects with MCI, baseline hypoperfusion in the right inferior parietal cortex, middle frontal cortex, and 
precuneus was associated with cognitive decline [62]. In cognitively normal subjects, reduced blood flow in the posterior cingulate cortex was associated with the development of subtle neuropsychological deficits, and discriminated subjects with cognitive decline from stable subjects with a sensitivity of $59 \%$ and a specificity of $65 \%$ [63]. More research is needed on the predictive value of ASL, as well as standardisation of processing streams and establishment of cut-offs for abnormality, before it can be used as an inclusion criterion in clinical trials.

Blood flow is closely coupled to brain glucose metabolism and hence ASL could potentially offer an MRI-based alternative to FDG-PET, although further research is needed $[60,64,65]$. The early frames of dynamically acquired amyloid PET images also provide information about cerebral blood flow [66]. These early frames also strongly correlate with the metabolic profiles obtained using FDG-PET [67-69]. Using the early frames of an amyloid PET as a functional measure, rather than a separate FDG-PET, avoids additional patient burden in terms of radiation or separate visits. However, it does require scanning immediately following tracer injection (Box 3 ).

\section{Box 3: Quantification of amyloid load from PET \\ Quantification of amyloid load from PET images can be performed with different types of measurements. The most commonly used parameter is the integrated signal in target-rich cortical regions compared with a target-poor region such as the cerebellum, subcortical white matter or pons, also referred to as the standardised uptake value ratio (SUVr). SUVr can be derived from static scans, typically a 20-minute acquisition $1 \mathrm{~h}$ after injection, when uptake of the tracer has plateaued. The choice of target regions of interest and reference regions for normalisation has led to a wide range of published SUVr cut-off values for subject amyloid status classification. Amyloid load can also be quantified more specifically with binding potential values or distribution volume ratios, which are derived from kinetic modelling. This requires a longer acquisition time, with dynamic scanning from the moment of tracer injection until the plateau phase. Due to the lower variability, lower sensitivity to flow, and ability to measure subtle longitudinal changes, fully quantitative measurements may be preferred over SUVr [150, 207]. Further research is needed to establish whether dynamic, rather than static, amyloid PET imaging is operationally practical and cost- effective for determining true binding potential in early proof-of- concept trials aiming to slow the rate of amyloid accumulation.}

\section{Changes in functional connectivity: resting state functional MRI}

Subjects with AD dementia may show decreased brain connectivity [70]. Evidence of early disruption of connectivity measures in the pre-clinical stage is emerging, although with conflicting results [71-75]. There is a paucity of evidence on the predictive value of resting state functional MRI (rs-fMRI) for clinical progression. Only studies in MCI have been performed, with mixed findings which may be due to differences in processing streams and end-points [76-79]. Although rs-fMRI has potential, larger studies are needed to identify sensitive rs-fMRI markers and to define normative values. At this stage, rs-fMRI is not recommended as an inclusion criterion for trials.

\section{Structural imaging}

Medial temporal lobe atrophy: a role in the pre-clinical phase?

Structural MRI provides in-vivo measures of global and regional brain volumes, such as the hippocampus and entorhinal cortex. Medial temporal lobe atrophy is a consistent finding in patients with $\mathrm{AD}$ dementia and can aid in the prediction of time to clinical progression in amyloid-positive subjects with MCI [80, 81]. Population-based studies have shown that hippocampal volume and hippocampal atrophy rates can predict future cognitive decline in cognitively normal subjects during long follow-up periods, in the order of 510 years [82-84] (Table 3). Recent data showed that cognitively normal subjects with hippocampal atrophy and positive amyloid PET were at risk of cognitive decline, whereas subjects with low hippocampal volume but negative for amyloid pathology were not, over a median follow-up of 6 years [85]. Importantly, regional brain volumes derived from structural MRI vary with age, head size, and scanner type in the absence of known pathology [86]. Defining cut-offs for abnormality using cross-sectional volumes should be corrected for these confounds. Due to large inter-individual variation in cross-sectional measures of hippocampal volume, also within the diagnostic group [87], the intra-individual rate of hippocampal volume loss over time has attracted growing interest as this approach negates the effects of inter-individual variability. A meta-analysis found an average rate of atrophy per year of $4.7 \%(95 \%$ CI $3.9-5.4)$ in $\mathrm{AD}$ dementia and $1.4 \%$ (95\% CI $0.5-2.3$ ) in healthy ageing, resulting in an average 3\% difference in atrophy per year [88]. These findings highlight the advantage of having a trial-readiness cohort in which longitudinal imaging data can be used to provide more accurate change measures to improve subject selection strategies for clinical trials.

The European Medicines Agency has officially qualified hippocampal volume as an enrichment biomarker 
Table 3 Predictive value of hippocampal measures for cognitive decline in cognitively normal subjects

\begin{tabular}{|c|c|c|c|c|c|c|}
\hline \multirow[t]{2}{*}{ Reference } & \multicolumn{4}{|l|}{ Study design } & \multirow[t]{2}{*}{ Measurement type } & \multirow[t]{2}{*}{ Main outcome } \\
\hline & Cohort & Size & $\begin{array}{l}\text { Follow- } \\
\text { up }\end{array}$ & $\begin{array}{l}\text { Mean } \\
\text { age }\end{array}$ & & \\
\hline $\begin{array}{l}\text { Burnham et al., } \\
2016 \text { [85] }\end{array}$ & $\mathrm{AlBL}$ & $N=573$ & 6 years & 73 & Hippocampal volume & $\begin{array}{l}\text { Subjects with low hippocampal volume and } \\
\text { evidence of amyloid pathology showed faster } \\
\text { cognitive decline compared with subjects with } \\
\text { normal biomarkers. Subjects with only decreased } \\
\text { hippocampal volume in the absence of amyloid } \\
\text { pathology did not show significant decline } \\
\text { compared to the normal biomarker group }\end{array}$ \\
\hline $\begin{array}{l}\text { den Heijer } \\
\text { et al., } 2010 \text { [83] }\end{array}$ & $\begin{array}{l}\text { Rotterdam study } \\
\text { (population-based) }\end{array}$ & $N=518$ & 8 years & $73-79$ & $\begin{array}{l}\text { Hippocampal } \\
\text { atrophy rate }\end{array}$ & $\begin{array}{l}\text { Hippocampal atrophy rates predict cognitive } \\
\text { decline in healthy subjects (HR 1.6, 1.2-2.3). }\end{array}$ \\
\hline $\begin{array}{l}\text { den Heijer } \\
\text { et al., } 2006 \text { [82] }\end{array}$ & $\begin{array}{l}\text { Rotterdam study } \\
\text { (population-based) }\end{array}$ & $N=511$ & 6 years & $73-79$ & Hippocampal volume & $\begin{array}{l}\text { Hippocampal volume associated with risk } \\
\text { of dementia (HR 3.0, 2.0-4.6). }\end{array}$ \\
\hline $\begin{array}{l}\text { Martin et al., } \\
2010[84]\end{array}$ & $\begin{array}{l}\text { University of } \\
\text { Kentucky } \\
\text { AD Centre }\end{array}$ & $N=71$ & 5 years & $78-84$ & $\begin{array}{l}\text { Hippocampal and } \\
\text { subregions volume; } \\
\text { entorhinal cortex } \\
\text { volume }\end{array}$ & $\begin{array}{l}\text { Greater atrophy in hippocampus (head and body) } \\
\text { and entorhinal cortex in subjects converting to } \\
\mathrm{MCl} \text {. AUC } 0.87 \text { for hippocampal head, } 0.84 \text { for } \\
\text { hippocampal body, } 0.79 \text { for entorhinal cortex. }\end{array}$ \\
\hline $\begin{array}{l}\text { Stoub et al., } \\
2005[94]\end{array}$ & $\begin{array}{l}\text { Rush Alzheimer's } \\
\text { Disease Center } \\
\text { (Chicago, USA) }\end{array}$ & $\begin{array}{l}N=58 \\
(\mathrm{CN} \text { and } \mathrm{MCl} \text { together })\end{array}$ & 5 years & 80 & $\begin{array}{l}\text { Hippocampal volume } \\
\text { and atrophy rates; } \\
\text { entorhinal cortex } \\
\text { volume and } \\
\text { atrophy rates }\end{array}$ & $\begin{array}{l}\text { Baseline entorhinal and slope of decline were } \\
\text { predictors for AD. Baseline hippocampal volume } \\
\text { and atrophy rates were not (after controlling for } \\
\text { entorhinal cortex). }\end{array}$ \\
\hline
\end{tabular}

$A D$ Alzheimer's disease, AIBL Australian Imaging, Biomarker and Lifestyle study, AUC area under the curve, $C N$ cognitively normal, $M C I$ mild cognitive impairment, $H R$ hazard ratio

for inclusion in clinical trials in subjects with MCI [89], and subsequent work has demonstrated that selection of subjects with smaller hippocampi will likely reduce the overall cost of a trial in amnestic MCI [28]. This work requires extension to even earlier disease stages.

Within the hippocampus, different sub-fields can be distinguished using high-resolution MRI sequences which may provide additional information beyond hippocampal volume [90]. Several studies have shown that CA1 specifically, and to a lesser extent also subiculum atrophy, is present at a very early stage of AD since it could be detected in cognitively normal individuals that later developed MCI or AD dementia [84, 91-93].

Decreased entorhinal cortex volume may also be a predictor of cognitive decline $[84,94]$. In a grouped sample of non-demented subjects (comprising cognitively normal and MCI subjects), baseline entorhinal cortex volume and rate of atrophy were predictors for dementia, whereas baseline hippocampal volume and atrophy rates were not when controlling for entorhinal cortex volume [94]. Similarly, a reduced volume of the anteromedial temporal cortex has been found to be associated with the development of MCI or AD dementia in cognitively normal subjects [95]. Although a measurable decrease in entorhinal cortex thickness may precede changes in hippocampal and amygdala volume by several years [96], measurement error will hamper implementation in large multi-centre studies.

\section{Atrophy markers beyond the hippocampal region}

Besides medial temporal atrophy, other brain regions that typically show atrophy in $\mathrm{AD}$ dementia patients may have (additional) predictive value for decline in early disease stages. Several unbiased whole-brain voxel-based studies have found an AD-like pattern of more atrophied regions (involving the temporal neocortex, posterior cingulate, and orbitofrontal cortex in addition to the medial temporal lobe) in cognitively normal subjects up to a decade before the onset of dementia $[97,98]$. More recently, software to reliably quantify cortical thickness in regions throughout the brain has become widely available. Reduced cortical thickness in the entorhinal, inferior, and middle temporal structures, where tau neurofibrillary tangles are most prominent prior to the emergence of cognitive symptoms, were proposed as an AD signature of atrophy, and these regions were associated with cognitive decline in cognitively normal subjects [99]. By comparing cortical thickness in patients with AD dementia with cognitively normal subjects, another group also identified a set of so-called "AD-signature regions" comprising precuneus and other parietal and frontal regions in addition to the inferior and medial temporal cortex [100]. Atrophy in these $\mathrm{AD}$-signature regions could aid in the prediction of cognitive decline in cognitively normal subjects [100], although the medial temporal lobe cortex thickness may be a stronger predictor of clinical progression [101]. Other groups employing similar strategies have also found that cortical thickness in varying regions can aid 
in predicting cognitive decline in cognitively normal subjects $[102,103]$. A recent study showed that the rates of 3-year grey matter volume changes in areas of the episodic memory network mirrored accelerated decline in episodic memory ability in pre-clinical AD [104].

Medial temporal lobe atrophy is typical of $\mathrm{AD}$ and is commonly associated with an amnestic presentation. Atypical variants of $\mathrm{AD}$ also exist with different cognitive profiles (pre-dominance of non-memory symptoms) and variations in atrophy patterns [105]. The extent to which atrophy corresponding to these variants is detectable in pre-clinical phases of the disease remains unknown. Tracking atrophy in association with cortices in addition to medial temporal lobe structures may help in identifying or filtering for atypical subtypes of AD.

\section{White matter tissue integrity: diffusion tensor imaging}

Alterations to white matter microstructure as measured with diffusion tensor imaging (DTI) can be detected in patients with AD dementia [106, 107], and subtle changes might already be observed in the pre-clinical stage $[108,109]$. In cognitively normal subjects, reductions in fractional anisotropy in the fornix [110] and precuneus [111] may predict progression to $\mathrm{MCI}$. A study in elderly subjects with small vessel disease found an increased risk of dementia after 5-year follow-up associated with increased hippocampal mean diffusivity [112]. Studies in patients with MCI have shown that predictive values for cognitive decline are often higher (above 75\%) in single-centre studies compared with multi-centre studies [113-117]. More research into standardisation of DTI acquisition and processing streams is necessary before DTI can be used for subject selection or stratification in multi-centre clinical trials.

\section{Neuroimaging specificity in the pre-dementia phase Differential diagnosis}

To use imaging biomarkers for trial enrichment in pre-dementia stages, they should ideally not only predict future cognitive decline but also be specific for the underlying disease that is being targeted. Molecular markers measuring protein aggregates in the brain may be the most specific for Alzheimer's pathology. However, amyloid pathology can also occur in Lewy body dementia (DLB) [118], and at advancing age in the absence of imminent cognitive decline. Tau pathology is also seen in DLB and MAPT mutation carriers [119], traumatic brain injury [120], and normal ageing [121], although deposition patterns and binding of tau PET ligands may be different. Atrophy of the medial temporal lobe can be seen in various neurodegenerative diseases, as well as in vascular dementia [122-125], although the patterns of loss within the medial temporal lobe may help distinguish AD from other diseases [126]. Conversely, concordance between imaging markers and cognition may erroneously seem discordant, with more educated subjects showing preserved cognition in the presence of extensive brain pathology, a concept that has been termed cognitive reserve [127].

\section{Combining neuroimaging and other biomarkers}

The above-mentioned studies highlight that to date there is no single biomarker fully specific for predicting imminent cognitive decline due to AD in non-demented subjects. There is increasing interest in using more than one biomarker for enrichment, and in such circumstances these can be applied either sequentially or in combination [28, 128, 129]. A statistical model can be developed in which multiple (imaging and non-imaging) biomarkers, along with demographic variables, baseline cognitive status, and APOE $\varepsilon 4$ carrier status, can be used to identify subjects at risk of clinical progression for inclusion in trials. Cost-effectiveness should also be assessed here in which the additional costs, time, and burden of acquiring additional biomarkers are weighed against the added predictive value. Some work has been done on this topic for trials in MCI [28, 29], but this needs to be extended to the pre-clinical phase.

\section{Vascular comorbidity: a partner in crime Vascular pathology: a catalyst of cognitive decline}

A plethora of vascular pathology can be detected with MRI [130]. White matter hyper-intensities on T2-weighted MRI and fluid attenuated inversion recovery (FLAIR) are considered to reflect small-vessel ischemic damage in the brain. Alternative mechanisms include blood-brain barrier dysfunction, failed interstitial fluid drainage, and processes causing ischaemic damage [130]. Even white matter that appears "normal" on FLAIR may show abnormalities on DTI and blood-brain barrier measures [131]. Regardless of the exact mechanism(s), white matter hyper-intensities represent tissue disruption and contribute to cognitive dysfunction independently of neurodegenerative mechanisms [16]. Population-based studies show a causal relationship between the extent of white matter hyper-intensities and the future risk of cognitive decline, including AD dementia [17]. White matter hyper-intensities can be assessed using visual rating scales $[132,133]$ or quantified using dedicated software.

Cerebral microbleeds are small areas of hemosiderin deposition that can be visualised as dot-like hypo-intensities on $\mathrm{T}^{*}$ and even better on (three-dimensional) susceptibility-weighted imaging (SWI) [130]. Microbleeds are thought to be caused by damage to small vessel walls due to hypertensive lipohyalinosis, fibrinoid necrosis, amyloid angiopathy, or a combination of these processes. These lesions increase with the burden of other small vessel disease features and are frequently detected in subjects 
with MCI and AD dementia [134]. In a population-based study, the presence of multiple microbleeds was associated with future decline on various cognitive domains and an increased risk of dementia, including the AD type [135]. Another study in cognitively normal subjects also demonstrated an association between the presence of multiple microbleeds and decline in executive functioning [136].

\section{Vascular pathology in clinical trials: when to exclude?}

When participants fulfil diagnostic criteria for vascular dementia [137], they are typically excluded from clinical trials in AD. To secure subjects with a high likelihood of Alzheimer-only pathology, many studies exclude subjects with varying amounts of vascular burden. The Alzheimer's Disease Neuroimaging Initiative (ADNI), for example, excluded all subjects with infarcts and multiple or strategic lacunes, whereas in clinical practice many AD patients have a variable amount of vascular pathology, and vascular lesions may catalyse the expression of cognitive impairment [39]. Current practice in clinical trials varies and no consensus to date has been reached to evaluate cases of mixed pathology. Excluding all cerebrovascular pathology in trials may be prudent in early (phase 1 and 2) studies which aim to establish proof of principle for specific $A D$ pathway interventions. In phase 3 trials, it has been argued that enrolled subjects should reflect normal clinical practice. A more realistic approach would be to exclude only those with severe cerebrovascular pathology and to look at effect modification by vascular comorbidity in a pre-defined subgroup analysis. The presence of cerebrovascular disease increases strongly with advancing age [17] and is thus a more likely comorbidity alongside amyloid and tau in elderly subjects. Young subjects with abnormal molecular markers may have more pure forms of AD pathology.

\section{Imaging as an outcome measure in trials}

In secondary prevention trials targeting pre-dementia $\mathrm{AD}$ it may be challenging to meet clinical end-points (e.g. progression to dementia) with reasonable sample sizes and duration of treatment, especially in the pre-clinical phase [138]. Therefore, there is an urgent need for outcome markers that reflect slowing or prevention of disease progression. The choice of imaging marker to be used as the outcome may depend on the treatment target. An imaging measure as a (secondary) outcome in multi-centre trials needs to be highly reproducible, standardised across scanning platforms (instrument and tracer), sensitive to change over time, and able to detect treatment effects (whether target engagement, efficacy, or safety). From a practical perspective, imaging biomarkers should be operationally straightforward to deploy in multi-centre studies, with low costs compared with (less effective) alternatives. Available evidence on these technical features of the neuroimaging measures will be discussed in the next paragraphs and is summarised in Table 1.

For official surrogacy qualification by regulatory agencies, an imaging marker should also demonstrate an association with clinical progression, such that any effects of the treatment on the marker predict clinical benefit of the therapy [139]. Currently, there is not enough evidence for any imaging marker to qualify as a primary outcome measure in trials.

\section{Molecular imaging \\ Amyloid PET}

For therapies targeting the amyloid cascade, amyloid PET provides an opportunity to assess target engagement. Rates of amyloid deposition on PET are in the order of $1-3 \%$ per year in cognitively normal subjects, with higher rates in subjects with increased amyloid loads at baseline and in APOE \&4 carriers [2, 33, 47, 140-143]. Some studies have suggested an inverted $\mathrm{U}$-shaped curve of amyloid accumulation dependent on baseline amyloid loads, with the highest accumulation rates in subjects with intermediate (but above normal positivity thresholds) amyloid load at baseline and lowest rates in subjects without any amyloid or those with highest amyloid loads $[2,4,140]$. These potential non-linear rates should be considered when planning interventional trials as they may be relevant for sample size calculations and assessment of intervention effects. For example, subjects with high (plateau phase) amyloid burden will not further accumulate amyloid, which might make it more difficult to observe treatment-related effects [144].

There are limited published data on the variability and standardisation of amyloid PET in multi-centre studies [145], although practical experience is being gained in current phase 3 trials [146]. There is more knowledge and experience from FDG-PET studies, which have been used for a longer time. Standardisation by means of phantom scanning and local calibration of scanners is mandatory for interpretation of data from multi-centre settings. Procedural control at imaging sites must ensure consistent and adequate scanner quality assurance, subject preparation, and camera placement and acquisition and reconstruction parameters. Test-retest variability for ${ }^{18} \mathrm{~F}$-based amyloid tracers is generally good (in the order of 1-5\%) [147-149]. However, in longitudinal studies, pathological changes and ageing can present additional variability beyond the tracer and system variance. Intra-subject variability can be high due to factors such as progressive deterioration in the subject's ability to remain still and managing subject movement during scan acquisition [145]. Moreover, changes in blood flow associated with disease progression or in response to therapy over the course of the study could confound 
measurements relying on the standardised uptake value ratio (SUVr) [150] (Box 3). Optimisation of reference regions, better management of technical factors, dynamic scanning, or correction for perfusion changes should reduce such within-subject variability and allow more accurate determination of change in brain amyloid burden. Subject-related factors such as patient movement and changes in blood flow are likely to be less prominent in trials in pre-clinical populations.

Several clinical trials have already used amyloid PET as an end-point in patients with mild to moderate AD dementia [146, 151]. Interestingly, in the recent phase 1 study of the monoclonal antibody aducanumab, clinical effects seemed to be more pronounced in subjects with greater reduction of amyloid plaques on PET, measured with SUVr [152]. It is not yet clear how much removal of amyloid is needed for a meaningful change in amyloid PET.

\section{Tau PET}

Tau PET tracers and data are emerging, but current implementation is limited based on costs, availability, standardisation, and specificity of tracers. Emerging data on novel tau tracers indicate that the signal-to-noise ratio of some tracers in $\mathrm{AD}$ is good and that the test-retest performance is robust (test-retest variability 1-4\%) [153]. Preliminary data on longitudinal patterns of tau accumulation in symptomatic $\mathrm{AD}$ have recently been published, showing heterogeneous longitudinal changes between subjects [154]. Recent evidence in cognitively normal subjects suggests that rates of tau accumulation are in the order of $0.5 \%$ per year in amyloid-positive subjects, while there was no tau accumulation in the cognitively normal group without amyloid [155]. The use of tau PET as an outcome marker in trials will face similar challenges as amyloid PET, and may be of particular relevance in trials specifically targeting tau accumulation. Further development is encouraged, as therapies targeting tau pathology are entering clinical trials [156].

\section{Functional imaging FDG-PET}

Several studies have examined the potential of FDG-PET as an outcome marker in clinical trials. FDG-PET measures show good reproducibility across scanners and in multi-centre settings, provided there is prior harmonisation across sites [157]. Older studies have estimated that to measure a reduction of $25 \%$ in progression with a power of $80 \%$ in an MCI population, $800-1200$ subjects are required per arm [158]. When optimising acquisition procedures and analysis methods in multi-centre studies, the number of subjects needed decreases considerably, to about 200 subjects per arm [158, 159]. No sample size estimates are available yet for pre-clinical populations. FDG-PET has already been used as imaging end-point in several clinical trials in subjects with AD dementia [151], but with the advent of amyloid tracers has become less attractive as multiple (fluorinated) PET tracers would increase the radiation dose. Early-frame dynamic amyloid PET and ASL provide possible alternatives [60, 64, 67-69].

\section{Arterial spin labelling}

Some studies have started to use ASL as secondary outcome measures in trials investigating the effects of physical exercise on cognitive decline, but these have not yet been published (e.g. PACE-2 study [160]). Cerebral blood flow might be affected by the administration of therapeutical agents, but the power of ASL in detecting these changes still remains to be assessed. Quantifying cerebral blood flow from ASL techniques is not trivial since the signal-to-noise ratio is generally low and the measurement is influenced by various factors such as bolus arrival time, arterial input function, underlying kinetics, and static tissue parameters such as blood equilibrium magnetisation, in addition to subject factors such as age and disease. These underlying physiological variables may also themselves be altered in AD. In single-centre and single-vendor studies, the reproducibility of ASL measures is high $[161,162]$ but the differences between implementations of ASL sequences by scanner vendors are substantial [163]. Guidelines for the performance of ASL in clinical settings have been established [164] but are yet to be validated in multi-centre trials. Together with recent research focusing on standardising ASL measures across vendors [165], this will facilitate the use of ASL in multi-centre settings in the future. Nevertheless, ASL measures remain extremely sensitive to small changes in acquisition parameters, rendering it difficult at present to use in longitudinal settings where software updates may result in such parameter changes [165].

\section{Resting state functional MRI}

Test-retest reliability and across-scanner reproducibility of resting state functional networks have been established [166]. Recent large-scale studies have started to address multi-site harmonisation issues for longitudinal studies [167, 168]. Despite efforts to standardise the method, fMRI is susceptible to different sources of variability including physiological noise, head movement, and analytical methods which require further optimisation [169]. Due to harmonisation issues in longitudinal and multi-centre settings, we suggest that rs-fMRI measures can at present only serve as an exploratory outcome measure in trials. rs-fMRI has already been used as a secondary outcome measure in clinical trials in subjects with $\mathrm{AD}$ dementia, and treatment-related effects were found on the default mode network over a 3- to 6 -month time period [170, 171]. rs-fMRI is currently also being used in multi-centre clinical trials in cognitively normal subjects at increased risk of $\mathrm{AD}$ (e.g. the A4 trial [8]). 


\section{Structural imaging}

\section{Grey matter atrophy}

Patients with AD dementia show a pattern of widespread cerebral atrophy. Measures of global cortical atrophy have been used as an outcome marker in clinical trials in $\mathrm{MCI}$ and $\mathrm{AD}$ dementia (e.g. [172-174]). Besides global measures, regional changes can also be examined. Regional changes in different brain regions will likely relate more or less strongly to changes in different cognitive instruments, depending on the cognitive domains they subserve [175].

Hippocampal atrophy rates are a good candidate to serve as an outcome marker in multi-centre clinical trials, as long as standardisation of image acquisition between centres, consistent within-subject scanner acquisition, and uniform post-processing methods are performed. Test-retest reliability of repeated manual and automated hippocampal measurements from the same scanner is usually high (test-retest variability 1-4\%) $[176,177]$, but some algorithms are more robust than others [178]. Efforts to standardise the measurement of hippocampal volumetry in multi-centre studies have been undertaken and it is now standard practice for trials to employ single algorithms and centralised analysis [89, 179]. With the establishment of the Harmonised Protocol for hippocampal segmentation, there is a new gold standard against which automated measurement may be validated [180]. Variability between scanners using the same acquisition protocol and measurement algorithm is low [176]. However, the agreement in terms of absolute volumes varies with acquisition protocols and field strength. For example, change in voxel size can lead to systematic errors in the range of $5 \%$ for hippocampal volume [181]. Methods to correct for these variabilities are being investigated [86].

Using data from the Australian Imaging, Biomarker and Lifestyle (AIBL) study, a sample size of 384 subjects per arm was estimated to be needed to detect $25 \%$ slowing of hippocampal atrophy rates over 18 months in subjects with pre-clinical AD with a power of 80\% [182]. These numbers will be larger when taking into account atrophy occurring with normal ageing, which should be considered [183]. Measures of hippocampal atrophy rates have already been used as (secondary) end-points in various clinical trials in $\mathrm{MCI}$ and mild $\mathrm{AD}$ dementia, with varying results [151].

\section{Diffusion tensor imaging}

To date, there is little evidence for the use of DTI measures in (multi-centre) clinical trials. Several studies have pointed to the variability of DTI measurements in multi-centre studies and the need for extensive site harmonisation and calibration prior to starting [184-186]. More work is needed on the optimisation of DTI measurements in multi-centre settings, which is now being addressed [187]. So far, longitudinal DTI measures have only sparsely been used as (secondary) outcomes in clinical trials [188].

\section{Monitoring of side-effects \\ Amyloid-related imaging abnormalities}

MRI scans play an important role in safety monitoring during clinical trials. An issue of particular importance in the Alzheimer's field is the occurrence of amyloid-related imaging abnormalities (ARIA) that have emerged in several anti-amyloid immunotherapy trials [189], although ARIA also occurs spontaneously-including in placebo arms [190]. ARIA consists of ARIA-E (parenchymal oedema or sulcal effusion) with signal hyper-intensities on FLAIR, and ARIA-H (cerebral microbleeds or superficial siderosis) with hypo-intensity due to hemosiderin on $\mathrm{T} 2 \%$-weighted or susceptibility-sensitive pulse sequences (Fig. 4). Adequate training for radiological reads is recommended for both ARIA-E and ARIA-H to ensure reliable detection of subtle cases and to maximise consistency between raters [191]. Severity of ARIA-E can be rated using dedicated rating scales [192]. Central assessment of the images is
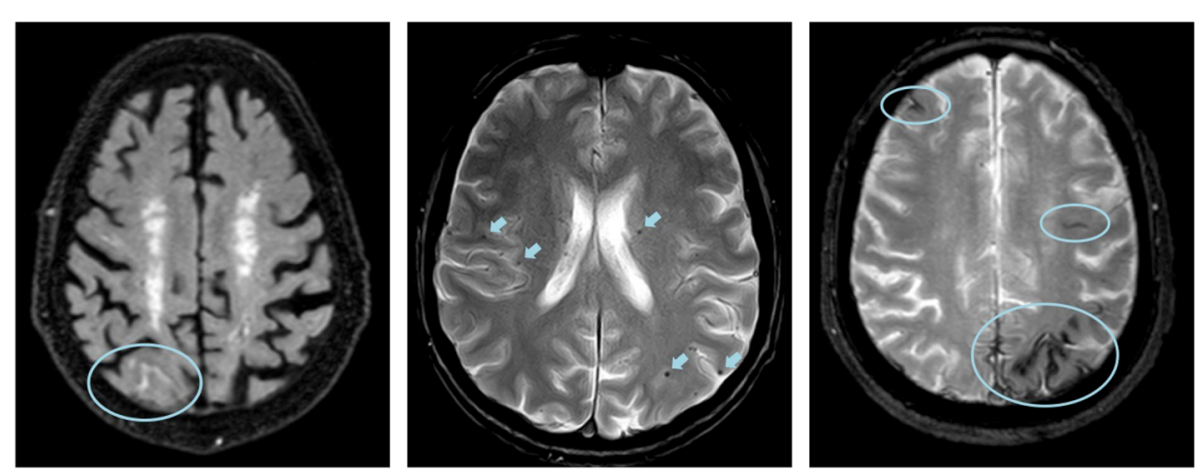

Fig. 4 Amyloid-related imaging abnormalities. Example of ARIA-E on FLAIR with sulcal effusion (left) and ARIA-H with multiple microbleeds (middle) and superficial siderosis (right) on $\mathrm{T} 2^{*}$ images 
recommended to guarantee quality control and to minimise differences in visual inspection and quantification.

The detection of ARIA-H is dependent on the pulse sequence contrast mechanism and parameters (e.g. echo time and slice thickness) as well as field strength [189]. The reported prevalence of microbleeds in $\mathrm{AD}$ dementia subjects ranges from $18 \%$ at $1 \mathrm{~T}$ to $71 \%$ at $7 \mathrm{~T}$ [193]. Since the presence of cerebral microbleeds confers a risk for future haemorrhage and development of ARIA, many trials limit the number of microbleeds at entry and monitor development of new microbleeds during the trial. A key consideration in the management of emergent ARIA cases during a trial is whether any clinical symptoms are associated with the radiological observations.

In pre-clinical $\mathrm{AD}$ populations, the baseline incidence and the frequency of spontaneous emergent ARIA is less well characterised than in clinically demented subjects, although one study observed a lower incidence than in MCI and AD dementia populations [194]. Although several large randomised clinical trials in pre-clinical AD populations have recently commenced, the ARIA findings are not yet available to the wider community.

\section{Regulatory perspective}

In 2011, following observations in the bapineuzumab trials [195] and recommendations from an Alzheimer's Association Round Table workgroup [189], the US Food and Drug Administration (FDA) requested the adoption of ARIA-based exclusion and discontinuation criteria for amyloid-targeting therapies. These limited the enrolment to subjects with at most four microbleeds at baseline and defined minimum acquisition standards. Since that time, for non-amyloid targeting mechanisms or if the ARIA risk for a particular compound or mechanism has been discharged in earlier trials, these criteria have been relaxed in some trials. Nevertheless, these recommendations have become a de facto standard. Systematic data collection and comparison between 2D-T2* and more sensitive sequences (e.g. 3D susceptibility-weighted imaging) is lacking. A well-controlled head-to-head comparison of the above $\mathrm{T} 2 *$ sequence prescription with a more sensitive alternative sequence would further the field's understanding of ARIA prevalence and evolution in the natural history and provide data to help establish meaningful and comparable cut-off criteria for these alternative sequences early in the disease course.

\section{Conclusions and practical implementation}

Neuroimaging allows visualisation of many aspects of the pathological cascade of $\mathrm{AD}$, including the presence of (pre-clinical) molecular pathology and downstream functional and structural markers of neurodegeneration before the onset of dementia. Information derived from imaging can aid in identifying non-demented subjects with an increased risk of future cognitive decline and disease progression to be included in secondary prevention trials. Combining information on underlying Alzheimer's pathology from amyloid PET (or CSF) with markers of neurodegeneration from structural MRI (or FDG-PET) provides the optimal strategy to identify subjects who are at highest risk of cognitive decline within the typical time frame of a clinical trial. Advanced functional and structural imaging techniques to predict cognitive decline at a pre-dementia stage hold promise but await further research and validation. Neuroimaging can help to characterise subjects in terms of comorbidities (e.g. cerebrovascular disease) or to define more homogeneous subgroups that can be used for stratification. Neuroimaging can also serve as a (secondary) outcome marker in trials. Amyloid PET can be used to assess target engagement for pharmacological compounds targeting the amyloid cascade, and structural imaging (or FDG-PET) can be used to assess possible treatment effects on neurodegeneration. Finally, imaging is crucial for monitoring safety and potential side effects, such as ARIA, during trials.

Trials in non-demented subjects are greatly facilitated by the establishment of a cohort of well-phenotyped subjects that can be included in clinical trials. This is an approach that has been taken by the European Prevention for Alzheimer's Dementia (EPAD; http://ep-ad.org/) study [196]. Within EPAD, subjects at elevated risk for AD are identified from various parent cohorts throughout Europe and enrolled into a longitudinal observational cohort study to serve as a trial-readiness cohort for proof-of-concept intervention studies. In addition to screening subjects, this trial-readiness cohort also provides an opportunity to apply run-in designs in which pre-trial longitudinal imaging can be used to determine within-subject rates of change, which increases the statistical power to detect treatment effects and reduces required sample sizes [197].

There are no formal guidelines on the use of neuroimaging measures in such trial-readiness cohorts of non-demented subjects. Some experience has been gathered through longitudinal imaging from multi-centre studies with large cohorts such as ADNI, with a strong focus on the MCI and dementia stages, and more recently with the AIBL study, with a focus on cognitively normal subjects $[198,199]$. In ADNI, the imaging protocol initially included structural MRI and a subgroup with amyloid PET, and was later complemented by FDG-PET and advanced MR techniques such as ASL, DTI, and rs-fMRI in ADNI-2. Subjects in ADNI-3 also undergo tau PET. In AIBL, the imaging protocol includes structural MRI and amyloid PET. Based on the literature reviewed in this paper, experience gained in other studies, and practical considerations, neuroimaging recommendations for the EPAD longitudinal cohort study have been formulated (Table 4). These recommendations 
Table 4 Imaging recommendations for EPAD longitudinal cohort study

\begin{tabular}{|c|c|c|c|c|c|}
\hline Imaging technique & Baseline & Baseline use & Follow-up & Follow-up use & Measures \\
\hline 3D T1 & Standard & $\begin{array}{l}\text { Exclusion criteria } \\
\text { Volumetric analysis } \\
\text { Visual rating pathology } \\
\text { Identify increased risk } \\
\text { of decline }\end{array}$ & Annually & $\begin{array}{l}\text { New incidental findings } \\
\text { Atrophy rates } \\
\text { Track visual pathology } \\
\text { Identify increased risk } \\
\text { of decline }\end{array}$ & $\begin{array}{l}\text { Volumetric analysis: brain structures } \\
\text { Visual: lacunes, atrophy }\end{array}$ \\
\hline 3D FLAIR & Standard & $\begin{array}{l}\text { Exclusion criteria } \\
\text { Volumetric analysis } \\
\text { Visual rating pathology } \\
\text { Subject stratification }\end{array}$ & Annually & $\begin{array}{l}\text { New incidental findings } \\
\text { Track visual pathology }\end{array}$ & $\begin{array}{l}\text { Volumetric analysis: white matter hyperintensities } \\
\text { Visual: lacunes, white matter hyperintensities, ARIA }\end{array}$ \\
\hline 2D-T2 & Standard & $\begin{array}{l}\text { Exclusion criteria } \\
\text { Visual rating pathology }\end{array}$ & Annually & $\begin{array}{l}\text { New incidental findings } \\
\text { Track visual pathology }\end{array}$ & Visual: lacunes, perivascular spaces, ARIA \\
\hline $\begin{array}{l}\text { 2D-T2* } \\
3 \mathrm{D}-\mathrm{T} 2^{*} / \mathrm{SWI}\end{array}$ & $\begin{array}{l}\text { Standard } \\
\text { Optional }\end{array}$ & $\begin{array}{l}\text { Exclusion criteria } \\
\text { Visual rating pathology }\end{array}$ & Annually & $\begin{array}{l}\text { New incidental findings } \\
\text { Track visual pathology }\end{array}$ & Visual: microbleeds and superficial siderosis \\
\hline DTI & Optional & Exploratory analysis & $\begin{array}{l}\text { Optional } \\
\text { 2-year }\end{array}$ & Changes in measures & Axial and radial diffusivity \\
\hline ASL & Optional & Exploratory analysis & $\begin{array}{l}\text { Optional } \\
\text { 2-year }\end{array}$ & Changes in measures & Whole brain and regional perfusion \\
\hline rs-fMRI & Optional & Exploratory analysis & $\begin{array}{l}\text { Optional } \\
\text { 2-year }\end{array}$ & Changes in measures & Connectivity measures \\
\hline $\begin{array}{l}\text { Amyloid PET } \\
\text { (static and dynamic) }\end{array}$ & Optional & Inclusion criteria & Optional & Changes in measures & $\begin{array}{l}\text { Visual: amyloid positive } \\
\text { Quantitative measures of } \\
\text { amyloid pathology } \\
\text { Dynamic scanning: perfusion measures }\end{array}$ \\
\hline
\end{tabular}

ARIA Amyloid-related imaging abnormalities, ASL arterial spin labelling, DTI diffusion tensor imaging, EPAD European Prevention for Alzheimer's Dementia, FLAIR fluid attenuated inversion recovery, $P E T$ positron emission tomography, rs-fMRI resting state functional magnetic resonance imaging

are based on a combination of desired information richness, patient burden, stratification capabilities, and provision of run-in data for trials. The recommended core imaging protocol for the EPAD longitudinal cohort study consists of yearly MRI scans including isotropic 3D-T1 and 3D-FLAIR sequences, as well as a short 2D-T2W and 2D-T2* sequence to assess neurodegenerative and vascular pathology. Advanced sequences such as 3D-T2*/SWI, DTI, ASL, and rs-fMRI will be acquired in subsets of patients depending on site interest and experience with acquisition methodology. Centralised assessment of the scans will be performed to guarantee quality control and maximise consistency in visual rating scales and quantification. All subjects in EPAD will undergo lumbar puncture to assess amyloid pathology in CSF. A large subgroup will also undergo amyloid PET, financed through the sister project Amyloid Imaging to Prevent AD (AMYPAD; http://amypad.eu/). Amyloid PET was prioritised as molecular imaging based on its potential to confirm and localise amyloid pathology, its broad availability and standardisation, and given that the initial molecular targets in upcoming proof-of-concept trials will likely address the amyloid pathway. Static amyloid PET imaging is currently the most common approach in clinical trials. Dynamic imaging, however, may be preferable to determine the true binding potential rather than an SUVr that may be biased by the choice of the reference region and flow effects. This argument becomes more relevant for longitudinal imaging where changes can be small and in treatment trials where flow alterations may occur. In addition, data from the initial uptake of the tracer can be used as a proxy to measure cerebral blood flow. As FDG-PET would add an additional radiation dose, it has not been included in the EPAD imaging protocol. While tau PET imaging is emerging, current implementation is limited due to costs, availability, and lack of standardisation. Development and accessibility of tau PET is encouraged as a potentially more proximate biomarker and predictor of disease progression and as therapies targeting tau enter clinical trials.

\section{Additional file}

Additional file 1: Table S1. Incidental findings on MRI. Table S2. Effect of amyloid on longitudinal MRI measures in cognitively normal subjects. (PDF $107 \mathrm{~kb}$ )

\footnotetext{
Abbreviations

AD: Alzheimer's disease; AMYPAD: Amyloid Imaging to Prevent Alzheimer's Disease; APOE: Apolipoprotein E; ARIA: Amyloid-related imaging abnormalities; ASL: Arterial spin labelling; Cl: Confidence interval; CSF: Cerebrospinal fluid; DLB: Lewy body dementia; DTI: Diffusion tensor imaging; EPAD: European Prevention for Alzheimer's Dementia; FDG: Fluorodeoxyglucose; FLAIR: Fluid attenuated inversion recovery; $\mathrm{MCl}$ : Mild cognitive impairment; MRI: Magnetic resonance imaging; PET: Positron emission tomography; PiB: Pittsburgh compound B; rsfMRI: Resting state functional magnetic resonance imaging: SUVr: Standardised uptake value ratio
}

Acknowledgements Not applicable. 


\section{Funding}

This project has received support from the following EU/EFPIA Innovative Medicines Initiatives (1 and 2) Joint Undertakings: EPAD grant no. 115736, AMYPAD grant no. 115952, and EMIF grant no. 115372. FB was supported by the NIHR biomedical research centre at UCLH. ME was supported by an ERC career integration grant (PCIG12-GA-2012-334259), LMUexcellent and Alzheimer Forschung Initiative. JW was supported by research grants from Fondation Leducq, Medical Research Council, British Heart Foundation and Wellcome Trust.

\section{Availability of data and materials}

Not applicable.

\section{Authors' contributions}

MtK and $\mathrm{SI}$ researched the literature and drafted the manuscript. AJS, NCF, GC, BNMvB, ME, CF, JDG, DH, MCl, AAL, JLM, CR, PS, MES, PJV, AW, JW, SH, and $\mathrm{FB}$ revised the manuscript for important intellectual content. All authors read and approved the final manuscript.

\section{Ethics approval and consent to participate}

Not applicable.

\section{Consent for publication}

Not applicable.

\section{Competing interests}

AJS is a full-time employee of Takeda Pharmaceuticals. MCl is a stock-holding employee of Eli Lilly and Company. Florbetapir F18 is owned and marketed by Avid/Lilly. Flortaucipir (18F-AV-1451) is an investigational agent under development by Avid/Lilly. DH is a full-time employee and stockholder of IXICO plc. ME is a full-time employee of Janssen Pharmaceutica. CF is a full-time employee of GE Healthcare. The remaining authors declare that they have no competing interests.

\section{Publisher's Note}

Springer Nature remains neutral with regard to jurisdictional claims in published maps and institutional affiliations.

\section{Author details}

${ }^{1}$ Department of Radiology and Nuclear Medicine, Neuroscience Campus Amsterdam, VU University Medical Center, Amsterdam, the Netherlands. ${ }^{2}$ Alzheimer Center \& Department of Neurology, Neuroscience Campus Amsterdam, VU University Medical Center, PO Box 7056, 1007 MB Amsterdam, the Netherlands. ${ }^{3}$ Takeda Pharmaceuticals Comparny, Cambridge, MA, USA. ${ }^{4}$ Eli Lilly and Company, Indianapolis, Indiana, USA. ${ }^{5}$ Dementia Research Centre, Department of Neurodegenerative Disease, UCL Institute of Neurology, London, UK. ${ }^{6}$ Institut National de la Santé et de la Recherche Médicale, Inserm UMR-S U1237, Université de Caen-Normandie, GIP Cyceron, Caen, France. ${ }^{7}$ Institute for Stroke and Dementia Research, Klinikum der Universität München, Ludwig-Maximilians-Universität LMU, Munich, Germany. ${ }^{8} \mathrm{GE}$ Healthcare Life Sciences, Amersham, UK. ${ }^{9}$ Barcelonaßeta Brain Research Center, Pasqual Maragall Foundation, Barcelona, Spain. ${ }^{10} \mathrm{IXICO}$ PIc, London, UK. ${ }^{11}$ Centre for Dementia Prevention, Centre for Clinical Brain Sciences, University of Edinburgh, Edinburgh, UK.

${ }^{12}$ Janssen Pharmaceutica NV, Beerse, Belgium. ${ }^{13}$ Dementia Research Centre, University of Edinburgh, Edinburgh, UK. ${ }^{14}$ Affidea Centre de Diagnostic Radiologique de Carouge, Geneva, Switzerland. ${ }^{15}$ Insititutes of Neurology and Healthcare Engineering, University College London, London, UK.

Received: 9 July 2018 Accepted: 10 October 2018

Published online: 30 October 2018

\section{References}

1. Scheltens P, Blennow K, Breteler MMB, de Strooper B, Frisoni GB, Salloway S, et al. Alzheimer's disease. Lancet. 2016:388:505-17.

2. Villain N, Chételat G, Grassiot B, Bourgeat P, Jones G, Ellis KA, et al. Regional dynamics of amyloid- $\beta$ deposition in healthy elderly, mild cognitive impairment and Alzheimer's disease: a voxelwise PiB-PET longitudinal study. Brain. 2012;135:2126-39.

3. Jack CR, Knopman DS, Jagust WJ, Petersen RC, Weiner MW, Aisen PS, et al. Tracking pathophysiological processes in Alzheimer's disease: an updated hypothetical model of dynamic biomarkers. Lancet Neurol. 2013;12:207-16.
4. Villemagne $V L$, Burnham S, Bourgeat P, Brown B, Ellis KA, Salvado O, et al. Amyloid $\beta$ deposition, neurodegeneration, and cognitive decline in sporadic Alzheimer's disease: a prospective cohort study. Lancet Neurol. 2013;12:357-67.

5. Villeneuve S, Rabinovici GD, Cohn-Sheehy BI, Madison C, Ayakta N, Ghosh PM, et al. Existing Pittsburgh compound-B positron emission tomography thresholds are too high: statistical and pathological evaluation. Brain. 2015; 138:2020-33.

6. Fox NC, Petersen RC. The G8 dementia research summit-a starter for eight? Lancet. 2013;382:1968-9.

7. Reiman EM, Langbaum JBS, Fleisher AS, Caselli RJ, Chen K, Ayutyanont N, et al. Alzheimer's Prevention Initiative: a plan to accelerate the evaluation of presymptomatic treatments. J Alzheimers Dis. 2011;26(Suppl 3):321-9.

8. Sperling RA, Rentz DM, Johnson KA, Karlawish J, Donohue M, Salmon DP, et al. The A4 study: stopping AD before symptoms begin? Sci Transl Med. 2014;6:228fs13.

9. Dubois B, Feldman HH, Jacova C, DeKosky ST, Barberger-Gateau P, Cummings J, et al. Research criteria for the diagnosis of Alzheimer's disease: revising the NINCDS-ADRDA criteria. Lancet Neurol. 2007;6:734-46.

10. Dubois B, Feldman HH, Jacova C, Hampel H, Molinuevo JL, Blennow K, et al. Advancing research diagnostic criteria for Alzheimer's disease: the IWG-2 criteria. Lancet Neurol. 2014;13:614-29.

11. Jack CR, Bennett DA, Blennow K, Carrillo MC, Dunn B, Haeberlein SB, et al. NIA-AA research framework: toward a biological definition of Alzheimer's disease. Alzheimers Dement. 2018;14:535-62.

12. Albert MS, DeKosky ST, Dickson D, Dubois B, Feldman HH, Fox NC, et al. The diagnosis of mild cognitive impairment due to Alzheimer's disease: recommendations from the National Institute on Aging-Alzheimer's Association workgroups on diagnostic guidelines for Alzheimer's disease. Alzheimers Dement. 2011;7:270-9.

13. Sperling RA, Aisen PS, Beckett LA, Bennett DA, Craft S, Fagan AM, et al. Toward defining the preclinical stages of Alzheimer's disease: recommendations from the National Institute on Aging-Alzheimer's Association workgroups on diagnostic guidelines for Alzheimer's disease. Alzheimers Dement. 2011;7:280-92.

14. Visser PJ, Tijms B. Brain amyloid pathology and cognitive function: Alzheimer disease without dementia? JAMA. 2017;317:2285-7.

15. Mortamais M, Ash JA, Harrison J, Kaye J, Kramer J, Randolph C, et al. Detecting cognitive changes in preclinical Alzheimer's disease: a review of its feasibility. Alzheimers Dement. 2017;13:468-92.

16. Jokinen H, Lipsanen J, Schmidt R, Fazekas F, Gouw AA, van der Flier WM, et al. Brain atrophy accelerates cognitive decline in cerebral small vessel disease: the LADIS study. Neurology. 2012;78:1785-92.

17. Prins ND, Scheltens $P$. White matter hyperintensities, cognitive impairment and dementia: an update. Nat Rev Neurol. 2015;11:157-65.

18. Lee S, Viqar F, Zimmerman ME, Narkhede A, Tosto G, Benzinger TLS, et al. White matter hyperintensities are a core feature of Alzheimer's disease: evidence from the dominantly inherited Alzheimer network. Ann Neurol. 2016;79:929-39.

19. Bachurin SO, Bovina EV, Ustyugov AA. Drugs in clinical trials for Alzheimer's disease: the major trends. Med Res Rev. 2017;37:1186-225.

20. Roberts $B R$, Lind $M$, Wagen $A Z$, Rembach $A$, Frugier $T$, Li Q-X, et al. Biochemically-defined pools of amyloid- $\beta$ in sporadic Alzheimer's disease: correlation with amyloid PET. Brain. 2017;140:1486-98.

21. Mattsson N, Insel PS, Donohue M, Landau S, Jagust WJ, Shaw LM, et al. Independent information from cerebrospinal fluid amyloid- $\beta$ and florbetapir imaging in Alzheimer's disease. Brain. 2015;138:772-83.

22. Palmqvist S, Mattsson N, Hansson O. Alzheimer's Disease Neuroimaging Initiative. Cerebrospinal fluid analysis detects cerebral amyloid- $\beta$ accumulation earlier than positron emission tomography. Brain. 2016;139:1226-36.

23. Schindler SE, Gray JD, Gordon BA, Xiong C, Batrla-Utermann R, Quan M, et al. Cerebrospinal fluid biomarkers measured by Elecsys assays compared to amyloid imaging. Alzheimers Dement. 2018.

24. Insel PS, Palmqvist S, Mackin RS, Nosheny RL, Hansson O, Weiner MW, et al. Assessing risk for preclinical $\beta$-amyloid pathology with $\mathrm{APOE}$, cognitive, and demographic information. Alzheimers Dement. 2016;4:76-84.

25. Nakamura A, Kaneko N, Villemagne VL, Kato T, Doecke J, Doré V, et al. High performance plasma amyloid- $\beta$ biomarkers for Alzheimer's disease. Nature. 2018:554:249-54.

26. Nabers A, Perna L, Lange J, Mons U, Schartner J, Güldenhaupt J, et al. Amyloid blood biomarker detects Alzheimer's disease. EMBO Mol Med. 2018;10:e8763. 
27. Yu P, Sun J, Wolz R, Stephenson D, Brewer J, Fox NC, et al. Operationalizing hippocampal volume as an enrichment biomarker for amnestic mild cognitive impairment trials: effect of algorithm, test-retest variability, and cut point on trial cost, duration, and sample size. Neurobiol Aging. 2014;35:808-18.

28. Wolz R, Schwarz AJ, Gray KR, Yu P, Hill DLG. Alzheimer's Disease Neuroimaging Initiative. Enrichment of clinical trials in $\mathrm{MCl}$ due to $\mathrm{AD}$ using markers of amyloid and neurodegeneration. Neurology. 2016;87:1235-41.

29. Frisoni GB, Bocchetta M, Chételat G, Rabinovici GD, de Leon MJ, Kaye J, et al. Imaging markers for Alzheimer disease: which vs how. Neurology. 2013; 81:487-500.

30. Morris JC, Roe CM, Grant EA, Head D, Storandt M, Goate AM, et al Pittsburgh compound B imaging and prediction of progression from cognitive normality to symptomatic Alzheimer disease. Arch Neurol. 2009; 66:1469-75.

31. Storandt M, Mintun M, Head D, Morris J. Cognitive decline and brain volume loss as signatures of cerebral amyloid- $\beta$ peptide deposition identified with Pittsburgh compound B: cognitive decline associated with aß deposition. Arch Neurol. 2009;66:1476-81.

32. Resnick SM, Sojkova J, Zhou Y, An Y, Ye W, Holt DP, et al. Longitudinal cognitive decline is associated with fibrillar amyloid-beta measured by [11C]PiB. Neurology. 2010;74:807-15.

33. Villemagne VL, Pike KE, Chételat G, Ellis KA, Mulligan RS, Bourgeat $P$, et al. Longitudinal assessment of $A B$ and cognition in aging and Alzheimer disease. Ann Neurol. 2011;69:181-92.

34. Lim YY, Ellis KA, Pietrzak RH, Ames D, Darby D, Harrington $K$, et al. Stronger effect of amyloid load than APOE genotype on cognitive decline in healthy older adults. Neurology. 2012;79:1645-52.

35. Lim $Y Y$, Maruff $P$, Pietrzak RH, Ames D, Ellis KA, Harrington $K$, et al. Effect of amyloid on memory and non-memory decline from preclinical to clinical Alzheimer's disease. Brain. 2014;137:221-31.

36. Kawas $\mathrm{CH}$, Greenia DE, Bullain SS, Clark CM, Pontecorvo MJ, Joshi AD, et al. Amyloid imaging and cognitive decline in nondemented oldest-old: the 90 + Study. Alzheimers Dement. 2013;9:199-203.

37. Doraiswamy PM, Sperling RA, Johnson K, Reiman EM, Wong TZ, Sabbagh MN, et al. Florbetapir F 18 amyloid PET and 36-month cognitive decline: a prospective multicenter study. Mol Psychiatry. 2014;19:1044-51.

38. Vemuri P, Lesnick TG, Przybelski SA, Knopman DS, Preboske GM, Kantarci K, et al. Vascular and amyloid pathologies are independent predictors of cognitive decline in normal elderly. Brain. 2015;138:761-71.

39. Petersen RC, Wiste HJ, Weigand SD, Rocca WA, Roberts RO, Mielke MM, et al. Association of elevated amyloid levels with cognition and biomarkers in cognitively normal people from the community. JAMA Neurol. 2016;73:85.

40. Donohue MC, Sperling RA, Petersen R, Sun C-K, Weiner MW, Aisen PS, et al. Association between elevated brain amyloid and subsequent cognitive decline among cognitively normal persons. JAMA. 2017;317:2305-16.

41. Rowe CC, Bourgeat $P$, Ellis KA, Brown B, Lim YY, Mulligan $R$, et al. Predicting Alzheimer disease with $\beta$-amyloid imaging: results from the Australian imaging, biomarkers, and lifestyle study of ageing. Ann Neurol. 2013;74:905-13.

42. Ewers $M$, Insel $P$, Jagust WJ, Shaw L, Trojanowski JQ, Aisen $P$, et al. CSF biomarker and PIB-PET-derived beta-amyloid signature predicts metabolic, gray matter, and cognitive changes in nondemented subjects. Cereb Cortex. 2012;22:1993-2004.

43. Dickerson BC, Wolk DA, Alzheimer's Disease Neuroimaging Initiative. Biomarker-based prediction of progression in $\mathrm{MCl}$ : comparison of $\mathrm{AD}$ signature and hippocampal volume with spinal fluid amyloid- $\beta$ and tau. Front Aging Neurosci. 2013;5:55.

44. Grothe MJ, Barthel H, Sepulcre J, Dyrba M, Sabri O, Teipel SJ, et al. In vivo staging of regional amyloid deposition. Neurology. 2017;89:2031-8.

45. Wirth M, Villeneuve S, Haase CM, Madison CM, Oh H, Landau SM, et al. Associations between Alzheimer disease biomarkers, neurodegeneration, and cognition in cognitively normal older people. JAMA Neurol. 2013;70:1512-9.

46. Mormino EC, Betensky RA, Hedden T, Schultz AP, Amariglio RE, Rentz DM, et al. Synergistic effect of $\beta$-amyloid and neurodegeneration on cognitive decline in clinically normal individuals. JAMA Neurol. 2014;71:1379-85.

47. Jack CR, Lowe VJ, Weigand SD, Wiste HJ, Senjem ML, Knopman DS, et al. Serial PIB and MRI in normal, mild cognitive impairment and Alzheimer's disease: implications for sequence of pathological events in Alzheimer's disease. Brain. 2009;132:1355-65.

48. Vos SJ, Xiong C, Visser PJ, Jasielec MS, Hassenstab J, Grant EA, et al. Preclinical Alzheimer's disease and its outcome: a longitudinal cohort study. Lancet Neurol. 2013;12:957-65.
49. Braak H, Braak E. Evolution of the neuropathology of Alzheimer's disease. Acta Neurol Scand. 1996;94:3-12.

50. Desikan RS, McEvoy LK, Thompson WK, Holland D, Brewer JB, Aisen PS, et al. Amyloid- $\beta$--associated clinical decline occurs only in the presence of elevated P-tau. Arch Neurol. 2012;69:709-13.

51. Villemagne $\mathrm{VL}$, Fodero-Tavoletti MT, Masters $\mathrm{CL}$, Rowe CC. Tau imaging: early progress and future directions. Lancet Neurol. 2015;14:114-24.

52. Hall B, Mak E, Cervenka S, Aigbirhio FI, Rowe JB, O'Brien JT. In vivo tau PET imaging in dementia: pathophysiology, radiotracer quantification, and a systematic review of clinical findings. Ageing Res Rev. 2017;36:50-63.

53. Betthauser J, Cody KA, Zammit MD, Murali D, Converse AK, Barnhart TE, et al. In vivo characterization and quantification of neurofibrillary tau PET radioligand [18F]MK-6240 in humans from Alzheimer's disease dementia to young controls. J Nucl Med jnumed. 2018:118.209650.

54. Schöll M, Lockhart SN, Schonhaut DR, O'Neil JP, Janabi M, Ossenkoppele R, et al. PET imaging of tau deposition in the aging human brain. Neuron. 2016:89:971-82.

55. Hanseeuw BJ, Betensky RA, Schultz AP, Papp KV, Mormino EC, Sepulcre J, et al. Fluorodeoxyglucose metabolism associated with tau-amyloid interaction predicts memory decline. Ann Neurol. 2017:81:583-96.

56. Mosconi L, Berti V, Glodzik L, Pupi A, De Santi S, de Leon MJ. Pre-clinical detection of Alzheimer's disease using FDG-PET, with or without amyloid imaging. J Alzheimers Dis. 2010;20:843-54.

57. Arbizu J, Festari C, Altomare D, Walker Z, Bouwman F, Rivolta J, et al. Clinical utility of FDG-PET for the clinical diagnosis in $\mathrm{MCl}$. Eur J Nucl Med Mol Imaging. 2018;45(9):1497-508.

58. Mosconi L, De Santi S, Li J, Tsui WH, Li Y, Boppana M, et al. Hippocampal hypometabolism predicts cognitive decline from normal aging. Neurobiol Aging. 2008;29:676-92

59. Ewers M, Brendel M, Rizk-Jackson A, Rominger A, Bartenstein P, Schuff N, et al. Reduced FDG-PET brain metabolism and executive function predict clinical progression in elderly healthy subjects. Neuroimage Clin. 2014;4:45-52.

60. Chen Y, Wolk DA, Reddin JS, Korczykowski M, Martinez PM, Musiek ES, et al. Voxel-level comparison of arterial spin-labeled perfusion MRI and FDG-PET in Alzheimer disease. Neurology. 2011;77:1977-85.

61. Binnewijzend MAA, Kuijer JPA, Benedictus MR, van der Flier WM, Wink AM, Wattjes MP, et al. Cerebral blood flow measured with 3D pseudocontinuous arterial spin-labeling MR imaging in Alzheimer disease and mild cognitive impairment: a marker for disease severity. Radiology. 2013;267:221-30.

62. Chao LL, Buckley ST, Kornak J, Schuff N, Madison C, Yaffe K, et al. ASL perfusion MRI predicts cognitive decline and conversion from $\mathrm{MCl}$ to dementia. Alzheimer Dis Assoc Disord. 2010;24:19-27.

63. Xekardaki A, Rodriguez C, Montandon M-L, Toma S, Tombeur E, Herrmann $\mathrm{FR}$, et al. Arterial spin labeling may contribute to the prediction of cognitive deterioration in healthy elderly individuals. Radiology. 2015;274:490-9.

64. Verfaillie SCJ, Adriaanse SM, Binnewijzend MAA, Benedictus MR, Ossenkoppele R, Wattjes MP, et al. Cerebral perfusion and glucose metabolism in Alzheimer's disease and frontotemporal dementia: two sides of the same coin? Eur Radiol. 2015:25:3050-9.

65. Fällmar D, Haller S, Lilja J, Danfors T, Kilander L, Tolboom N, et al. Arterial spin labeling-based Z-maps have high specificity and positive predictive value for neurodegenerative dementia compared to FDG-PET. Eur Radiol. 2017;27(10):4237-46.

66. Scott CJ, Jiao J, Melbourne A, Schott JM, Hutton BF, Ourselin S. ASLincorporated pharmacokinetic modelling of PET data with reduced acquisition time: application to amyloid imaging. Medical Image Computing and Computer-Assisted Intervention-MICCAI 2016. Cham: Springer; 2016. p. 406-13. Available from: https://link.springer.com/chapter/10.1007/978-3319-46726-9_47. [cited 2017 May 31]

67. Rostomian AH, Madison C, Rabinovici GD, Jagust WJ. Early 11C-PIB frames and 18F-FDG PET measures are comparable: a study validated in a cohort of AD and FTLD patients. J Nucl Med. 2011;52:173-9.

68. Hsiao I-T, Huang C-C, Hsieh C-J, Hsu W-C, Wey S-P, Yen T-C, et al. Correlation of early-phase 18F-florbetapir (AV-45/Amyvid) PET images to FDG images: preliminary studies. Eur J Nucl Med Mol Imaging. 2012;39:613-20.

69. Tiepolt S, Hesse S, Patt M, Luthardt J, Schroeter ML, Hoffmann K-T, et al. Early [(18)F]florbetaben and [(11)C]PiB PET images are a surrogate biomarker of neuronal injury in Alzheimer's disease. Eur J Nucl Med Mol Imaging. 2016; 43:1700-9.

70. Barkhof F, Haller S, Rombouts SARB. Resting-state functional MR imaging: a new window to the brain. Radiology. 2014;272:29-49. 
71. Sheline YI, Raichle ME, Snyder AZ, Morris JC, Head D, Wang S, et al. Amyloid plaques disrupt resting state default mode network connectivity in cognitively normal elderly. Biol Psychiatry. 2010;67:584-7.

72. Mormino EC, Smiljic A, Hayenga AO, Onami SH, Greicius MD, Rabinovici GD, et al. Relationships between beta-amyloid and functional connectivity in different components of the default mode network in aging. Cereb Cortex. 2011;21:2399-407.

73. Lim HK, Nebes R, Snitz B, Cohen A, Mathis C, Price J, et al. Regional amyloid burden and intrinsic connectivity networks in cognitively normal elderly subjects. Brain. 2014:137:3327-38.

74. Elman JA, Madison CM, Baker SL, Vogel JW, Marks SM, Crowley S, et al. Effects of beta-amyloid on resting state functional connectivity within and between networks reflect known patterns of regional vulnerability. Cereb Cortex. 2016;26:695-707.

75. Chhatwal JP, Schultz AP, Johnson KA, Hedden T, Jaimes S, Benzinger TLS, et al. Preferential degradation of cognitive networks differentiates Alzheimer's disease from ageing. Brain. 2018;141:1486-500.

76. Bai F, Xie C, Watson DR, Shi Y, Yuan Y, Wang Y, et al. Aberrant hippocampal subregion networks associated with the classifications of aMCI subjects: a longitudinal resting-state study. PLoS One. 2011;6:e29288.

77. Binnewijzend MAA, Schoonheim MM, Sanz-Arigita E, Wink AM, van der Flier WM, Tolboom N, et al. Resting-state fMRI changes in Alzheimer's disease and mild cognitive impairment. Neurobiol Aging. 2012;33:2018-28.

78. Wang $Z$, Liang $P$, Jia $X$, Jin $G$, Song $H$, Han $Y$, et al. The baseline and longitudinal changes of PCC connectivity in mild cognitive impairment: a combined structure and resting-state fMRI study. PLoS One. 2012;7:e36838.

79. Serra L, Cercignani M, Mastropasqua C, Torso M, Spanò B, Makovac E, et al. Longitudinal changes in functional brain connectivity predicts conversion to Alzheimer's disease. J Alzheimers Dis. 2016;51:377-89.

80. Jack CR, Wiste HJ, Vemuri P, Weigand SD, Senjem ML, Zeng G, et al. Brain beta-amyloid measures and magnetic resonance imaging atrophy both predict time-to-progression from mild cognitive impairment to Alzheimer's disease. Brain. 2010;133:3336-48.

81. van Rossum IA, Vos SJB, Burns $L, K$ nol DL, Scheltens $P$, Soininen $H$, et al. Injury markers predict time to dementia in subjects with $\mathrm{MCl}$ and amyloid pathology. Neurology. 2012;79:1809-16.

82. den Heijer T, Geerlings MI, Hoebeek FE, Hofman A, Koudstaal PJ, Breteler MMB. Use of hippocampal and amygdalar volumes on magnetic resonance imaging to predict dementia in cognitively intact elderly people. Arch Gen Psychiatry. 2006;63:57-62.

83. den Heijer T, van der Lijn F, Koudstaal PJ, Hofman A, van der Lugt A, Krestin $G P$, et al. A 10-year follow-up of hippocampal volume on magnetic resonance imaging in early dementia and cognitive decline. Brain. 2010;133: $1163-72$.

84. Martin SB, Smith CD, Collins HR, Schmitt FA, Gold BT. Evidence that volume of anterior medial temporal lobe is reduced in seniors destined for mild cognitive impairment. Neurobiol Aging. 2010;31:1099-106.

85. Burnham SC, Bourgeat P, Doré V, Savage G, Brown B, Laws S, et al. Clinical and cognitive trajectories in cognitively healthy elderly individuals with suspected non-Alzheimer's disease pathophysiology (SNAP) or Alzheimer's disease pathology: a longitudinal study. Lancet Neurol. 2016;15:1044-53.

86. Potvin O, Mouiha A, Dieumegarde L, Duchesne S. Alzheimer's Disease Neuroimaging Initiative. Normative data for subcortical regional volumes over the lifetime of the adult human brain. Neurolmage. 2016;137:9-20.

87. Frankó E, Joly O, Alzheimer's Disease Neuroimaging Initiative. Evaluating Alzheimer's disease progression using rate of regional hippocampal atrophy. PLoS One. 2013;8:e71354.

88. Barnes J, Bartlett JW, van de Pol LA, Loy CT, Scahill RI, Frost C, et al. A metaanalysis of hippocampal atrophy rates in Alzheimer's disease. Neurobiol Aging. 2009;30:1711-23.

89. Hill DLG, Schwarz AJ, Isaac M, Pani L, Vamvakas S, Hemmings R, et al. Coalition Against Major Diseases/European Medicines Agency biomarker qualification of hippocampal volume for enrichment of clinical trials in predementia stages of Alzheimer's disease. Alzheimers Dement. 2014;10: 421-429.e3.

90. de Flores R, La Joie R, Chételat G. Structural imaging of hippocampal subfields in healthy aging and Alzheimer's disease. Neuroscience. 2015;309: $29-50$.

91. Csernansky JG, Wang L, Swank J, Miller JP, Gado M, McKeel D, et al. Preclinical detection of Alzheimer's disease: hippocampal shape and volume predict dementia onset in the elderly. Neurolmage. 2005;25:783-92.
92. Apostolova LG, Mosconi L, Thompson PM, Green AE, Hwang KS, Ramirez A, et al. Subregional hippocampal atrophy predicts Alzheimer's dementia in the cognitively normal. Neurobiol Aging. 2010;31:1077-88.

93. Achterberg $\mathrm{HC}$, van der Lijn F, den Heijer T, Vernooij MW, Ikram MA, Niessen WJ, et al. Hippocampal shape is predictive for the development of dementia in a normal, elderly population. Hum Brain Mapp. 2014;35: 2359-71.

94. Stoub TR, Bulgakova M, Leurgans S, Bennett DA, Fleischman D, Turner DA, et al. MRI predictors of risk of incident Alzheimer disease: a longitudinal study. Neurology. 2005;64:1520-4.

95. Smith CD, Chebrolu H, Wekstein DR, Schmitt FA, Jicha GA, Cooper G, et al Brain structural alterations before mild cognitive impairment. Neurology. 2007;68:1268-73.

96. Younes L, Albert M, Miller MI. BIOCARD Research Team. Inferring changepoint times of medial temporal lobe morphometric change in preclinical Alzheimer's disease. Neuroimage Clin. 2014;5:178-87.

97. Hall AM, Moore RY, Lopez OL, Kuller L, Becker JT. Basal forebrain atrophy is a presymptomatic marker for Alzheimer's disease. Alzheimers Dement. 2008;4:271-9.

98. Tondelli M, Wilcock GK, Nichelli P, De Jager CA, Jenkinson M, Zamboni G. Structural MRI changes detectable up to ten years before clinical Alzheimer's disease. Neurobiol Aging. 2012;33:825.e25-36.

99. Jack CR, Wiste HJ, Weigand SD, Knopman DS, Mielke MM, Vemuri P, et al. Different definitions of neurodegeneration produce similar amyloid/ neurodegeneration biomarker group findings. Brain. 2015;138:3747-59.

100. Dickerson BC, Stoub TR, Shah RC, Sperling RA, Killiany RJ, Albert MS, et al. Alzheimer-signature MRI biomarker predicts AD dementia in cognitively normal adults. Neurology. 2011;76:1395-402

101. Verfaillie SCJ, Tijms B, Versteeg A, Benedictus MR, Bouwman FH, Scheltens P, et al. Thinner temporal and parietal cortex is related to incident clinical progression to dementia in patients with subjective cognitive decline. Alzheimers Dement (Amst). 2016:5:43-52.

102. Chiang GC, Insel PS, Tosun D, Schuff N, Truran-Sacrey D, Raptentsetsang S, et al. Identifying cognitively healthy elderly individuals with subsequent memory decline by using automated MR temporoparietal volumes. Radiology. 2011;259:844-51.

103. Pettigrew C, Soldan A, Zhu Y, Wang M-C, Moghekar A, Brown T, et al. Cortical thickness in relation to clinical symptom onset in preclinical $A D$. Neuroimage Clin. 2016;12:116-22.

104. Araque Caballero MÁ, Klöppel S, Dichgans M, Ewers M, Initiative A's DN. Spatial patterns of longitudinal gray matter change as predictors of concurrent cognitive decline in amyloid positive healthy subjects. J Alzheimers Dis. 2016;55:343-58.

105. Whitwell JL, Dickson DW, Murray ME, Weigand SD, Tosakulwong N, Senjem $\mathrm{ML}$, et al. Neuroimaging correlates of pathologically defined subtypes of Alzheimer's disease: a case-control study. Lancet Neurol. 2012;11:868-77.

106. Chua TC, Wen W, Slavin MJ, Sachdev PS. Diffusion tensor imaging in mild cognitive impairment and Alzheimer's disease: a review. Curr Opin Neurol. 2008;21:83-92.

107. Clerx L, Visser PJ, Verhey F, Aalten P. New MRI markers for Alzheimer's disease: a meta-analysis of diffusion tensor imaging and a comparison with medial temporal lobe measurements. J Alzheimers Dis. 2012;29:405-29.

108. Molinuevo JL, Ripolles P, Simó M, Lladó A, Olives J, Balasa M, et al. White matter changes in preclinical Alzheimer's disease: a magnetic resonance imaging-diffusion tensor imaging study on cognitively normal older people with positive amyloid $\beta$ protein 42 levels. Neurobiol Aging. 2014;35:267180.

109. Racine AM, Adluru N, Alexander AL, Christian BT, Okonkwo OC, Oh J, et al. Associations between white matter microstructure and amyloid burden in preclinical Alzheimer's disease: a multimodal imaging investigation. Neurolmage Clin. 2014;4:604-14.

110. Oishi K, Mielke MM, Albert M, Lyketsos CG, Mori S. The Fornix sign: a potential sign for Alzheimer's disease based on diffusion tensor imaging. J Neuroimaging. 2012;22:365-74.

111. Zhuang L, Sachdev PS, Trollor JN, Kochan NA, Reppermund S, Brodaty H, et al. Microstructural white matter changes in cognitively normal individuals at risk of amnestic $\mathrm{MCl}$. Neurology. 2012;79:748-54.

112. van Uden IWM, Tuladhar AM, van der Holst HM, van Leijsen EMC, van Norden AGW, de Laat KF, et al. Diffusion tensor imaging of the hippocampus predicts the risk of dementia; the RUN DMC study. Hum Brain Mapp. 2016;37:327-37. 
113. Scola E, Bozzali M, Agosta F, Magnani G, Franceschi M, Sormani MP, et al. A diffusion tensor MRI study of patients with $\mathrm{MCl}$ and $\mathrm{AD}$ with a 2-year clinical follow-up. J Neurol Neurosurg Psychiatry. 2010;81:798-805.

114. Mielke MM, Okonkwo OC, Oishi K, Mori S, Tighe S, Miller MI, et al. Fornix integrity and hippocampal volume predict memory decline and progression to Alzheimer's disease. Alzheimers Dement. 2012;8:105-13.

115. Douaud G, Menke RAL, Gass A, Monsch AU, Rao A, Whitcher B, et al. Brain microstructure reveals early abnormalities more than two years prior to clinical progression from mild cognitive impairment to Alzheimer's disease. J Neurosci. 2013;33:2147-55.

116. Selnes P, Aarsland D, Bjørnerud A, Gjerstad L, Wallin A, Hessen E, et al. Diffusion tensor imaging surpasses cerebrospinal fluid as predictor of cognitive decline and medial temporal lobe atrophy in subjective cognitive impairment and mild cognitive impairment. J Alzheimers Dis. 2013;33:723-36.

117. Brueggen K, Barkhof F, Hausner L, Filippi M, Nestor PJ, Hauenstein K, et al. Basal forebrain and hippocampus as predictors of conversion to Alzheimer's disease in patients with mild cognitive impairment-a multicenter DTI and volumetry study. J Alzheimers Dis. 2015;48:197-204.

118. Donaghy P, Thomas AJ, O'Brien JT. Amyloid PET imaging in Lewy body disorders. Am J Geriatr Psychiatry. 2015;23:23-37.

119. Smith $R$, Puschmann A, Schöll M, Ohlsson $T$, van Swieten J, Honer $M$, et al. 18F-AV-1451 tau PET imaging correlates strongly with tau neuropathology in MAPT mutation carriers. Brain. 2016;139:2372-9.

120. Barrio JR, Small GW, Wong K-P, Huang S-C, Liu J, Merrill DA, et al. In vivo characterization of chronic traumatic encephalopathy using [F-18]FDDNP PET brain imaging. Proc Natl Acad Sci. 2015;112:E2039-47.

121. Crary JF, Trojanowski JQ, Schneider JA, Abisambra JF, Abner EL, Alafuzoff I, et al. Primary age-related tauopathy (PART): a common pathology associated with human aging. Acta Neuropathol. 2014;128:755-66.

122. Barnes J, Whitwell J, Frost C, Josephs K, Rossor M, Fox N. Measurements of the amygdala and hippocampus in pathologically confirmed Alzheimer disease and frontotemporal lobar degeneration. Arch Neurol. 2006;63:1434-9.

123. Bastos-Leite AJ, van der FWM, van SECW, Staekenborg SS, Scheltens P, Barkhof F. The contribution of medial temporal lobe atrophy and vascular pathology to cognitive impairment in vascular dementia. Stroke. 2007;38:3182-5.

124. de Souza LC, Chupin M, Bertoux M, Lehéricy S, Dubois B, Lamari F, et al. Is hippocampal volume a good marker to differentiate Alzheimer's disease from frontotemporal dementia? J Alzheimers Dis. 2013;36:57-66.

125. Harper L, Barkhof F, Scheltens P, Schott JM, Fox NC. An algorithmic approach to structural imaging in dementia. J Neurol Neurosurg Psychiatry. 2014;85:692-8

126. Likeman M, Anderson VM, Stevens JM, Waldman AD, Godbolt AK, Frost C, et al. Visual assessment of atrophy on magnetic resonance imaging in the diagnosis of pathologically confirmed young-onset dementias. Arch Neurol. 2005;62:1410-5.

127. Stern Y. Cognitive reserve in ageing and Alzheimer's disease. Lancet Neurol. 2012:11:1006-12.

128. Vos S, van Rossum I, Burns L, Knol D, Scheltens P, Soininen H, et al. Test sequence of CSF and MRI biomarkers for prediction of $A D$ in subjects with MCl. Neurobiol Aging. 2012;33:2272-81.

129. Besson FL, La Joie R, Doeuvre L, Gaubert M, Mézenge F, Egret S, et al. Cognitive and brain profiles associated with current neuroimaging biomarkers of preclinical Alzheimer's disease. J Neurosci. 2015;35:10402-11.

130. Wardlaw JM, Smith EE, Biessels GJ, Cordonnier C, Fazekas F, Frayne R, et al. Neuroimaging standards for research into small vessel disease and its contribution to ageing and neurodegeneration. Lancet Neurol. 2013;12:822-38.

131. Muñoz Maniega S, Chappell FM, Valdés Hernández MC, Armitage PA, Makin SD, Heye AK, et al. Integrity of normal-appearing white matter: influence of age, visible lesion burden and hypertension in patients with small-vessel disease. J Cereb Blood Flow Metab. 2017;37:644-56.

132. Fazekas F, Chawluk JB, Alavi A, Hurtig HI, Zimmerman RA. MR signal abnormalities at 1.5 T in Alzheimer's dementia and normal aging. Am J Neuroradiol. 1987;8:421-6.

133. Wahlund LO, Barkhof F, Fazekas F, Bronge L, Augustin M, Sjögren M, et al. A new rating scale for age-related white matter changes applicable to MRI and CT. Stroke. 2001;32:1318-22.

134. Cordonnier C, van der Flier WM. Brain microbleeds and Alzheimer's disease: innocent observation or key player? Brain. 2011;134:335-44.

135. Akoudad S, Wolters FJ, Viswanathan A, de Bruijn RF, van der Lugt A, Hofman A, et al. Association of cerebral microbleeds with cognitive decline and dementia. JAMA Neurol. 2016;73:934-43.
136. Meier IB, Gu Y, Guzaman VA, Wiegman AF, Schupf N, Manly JJ, et al. Lobar microbleeds are associated with a decline in executive functioning in older adults. Cerebrovasc Dis. 2014;38:377-83.

137. van Straaten ECW, Scheltens P, Knol DL, van Buchem MA, van Dijk EJ, Hofman PAM, et al. Operational definitions for the NINDS-AIREN criteria for vascular dementia: an interobserver study. Stroke. 2003;34:1907-12.

138. Ritchie K, Ropacki M, Albala B, Harrison J, Kaye J, Kramer J, et al. Recommended cognitive outcomes in preclinical Alzheimer's disease: consensus statement from the European Prevention of Alzheimer's Dementia project. Alzheimers Dement. 2017;13:186-95.

139. Biomarkers Definitions Working Group. Biomarkers and surrogate endpoints: preferred definitions and conceptual framework. Clin Pharmacol Ther. 2001; 69:89-95.

140. Jack CR, Wiste HJ, Lesnick TG, Weigand SD, Knopman DS, Vemuri $P$, et al. Brain $\beta$-amyloid load approaches a plateau. Neurology. 2013;80:890-6.

141. Sojkova J, Beason-Held L, Zhou Y, An Y, Kraut MA, Ye W, et al. Longitudinal cerebral blood flow and amyloid deposition: an emerging pattern? J Nucl Med. 2008;49:1465-71.

142. Vlassenko AG, Mintun MA, Xiong C, Sheline YI, Goate AM, Benzinger TLS, et al. Amyloid-beta plaque growth in cognitively normal adults: longitudinal [11C]Pittsburgh compound B data. Ann Neurol. 2011;70:857-61.

143. Chételat G, La Joie R, Villain N, Perrotin A, de La Sayette V, Eustache F, et al. Amyloid imaging in cognitively normal individuals, at-risk populations and preclinical Alzheimer's disease. Neurolmage Clin. 2013;2:356-65.

144. Villemagne VL, Rowe CC, Barnham KJ, Cherny R, Woodward M, Bozinosvski $S$, et al. A randomized, exploratory molecular imaging study targeting amyloid $\beta$ with a novel 8-OH quinoline in Alzheimer's disease: the PBT2-204 IMAGINE study. Alzheimers Dement (N Y). 2017:3:622-35.

145. Schmidt ME, Chiao P, Klein G, Matthews D, Thurfjell L, Cole PE, et al. The influence of biological and technical factors on quantitative analysis of amyloid PET: points to consider and recommendations for controlling variability in longitudinal data. Alzheimers Dement. 2015;11:1050-68.

146. Fleisher AS, Joshi AD, Sundell KL, Chen Y-F, Kollack-Walker S, Lu M, et al. Use of white matter reference regions for detection of change in florbetapir positron emission tomography from completed phase 3 solanezumab trials. Alzheimers Dement. 2017;13(10):1117-24.

147. Villemagne VL, Ong K, Mulligan RS, Holl G, Pejoska S, Jones G, et al. Amyloid imaging with (18)F-florbetaben in Alzheimer disease and other dementias. J Nucl Med. 2011;52:1210-7.

148. Joshi AD, Pontecorvo MJ, Clark CM, Carpenter AP, Jennings DL, Sadowsky $\mathrm{CH}$, et al. Performance characteristics of amyloid PET with florbetapir $\mathrm{F} 18$ in patients with alzheimer's disease and cognitively normal subjects. J Nucl Med. 2012;53:378-84.

149. Vandenberghe R, Adamczuk K, Dupont P, Laere KV, Chételat G. Amyloid PET in clinical practice: its place in the multidimensional space of Alzheimer's disease. Neurolmage Clin. 2013;2:497-511.

150. van Berckel BNM, Ossenkoppele R, Tolboom N, Yaqub M, Foster-Dingley JC, Windhorst $A D$, et al. Longitudinal amyloid imaging using 11C-PiB: methodologic considerations. J Nucl Med. 2013;54:1570-6.

151. Cash DM, Rohrer JD, Ryan NS, Ourselin S, Fox NC. Imaging endpoints for clinical trials in Alzheimer's disease. Alzheimers Res Ther. 2014;6:87.

152. Sevigny J, Chiao P, Bussière T, Weinreb PH, Williams L, Maier M, et al. The antibody aducanumab reduces $A \beta$ plaques in Alzheimer's disease. Nature. 2016;537:50-6.

153. Chiotis K, Saint-Aubert L, Savitcheva I, Jelic V, Andersen $P$, Jonasson $M$, et al. Imaging in-vivo tau pathology in Alzheimer's disease with THK5317 PET in a multimodal paradigm. Eur J Nucl Med Mol Imaging. 2016;43:1686-99.

154. Chiotis K, Saint-Aubert L, Rodriguez-Vieitez E, Leuzy A, Almkvist O, Savitcheva I, et al. Longitudinalchanges of tau PET imaging in relation to hypometabolism in prodromal and Alzheimer's disease dementia. Mol Psychiatry. 2018;23:1666-1673.

155. Jack CR, Wiste HJ, Schwarz CG, Lowe VJ, Senjem ML, Vemuri P, et al. Longitudinal tau PET in ageing and Alzheimer's disease. Brain. 2018;141: 1517-28.

156. Li C, Götz J. Tau-based therapies in neurodegeneration: opportunities and challenges. Nat Rev Drug Discov. 2017;16(12):863-83.

157. Joshi A, Koeppe RA, Fessler JA. Reducing between scanner differences in multi-center PET studies. Neurolmage. 2009:46:154-9.

158. Schmidt ME, Matthews D, Andrews R, Mosconi L. Positron emission tomography in Alzheimer disease: diagnosis and use as biomarker endpoints. In: RA MA, editor. Translational neuroimaging: tools for CNS drug 
discovery, development and treatment: Academic Press; 2013. p. 131-74 Available from: http://www.sciencedirect.com/science/article/pii/ B9780123869456000056. [cited 2015 Aug 20].

159. Chen K, Langbaum JBS, Fleisher AS, Ayutyanont N, Reschke C, Lee W, et al. Twelve-month metabolic declines in probable Alzheimer's disease and amnestic mild cognitive impairment assessed using an empirically predefined statistical region-of-interest: findings from the Alzheimer's Disease Neuroimaging Initiative. Neurolmage. 2010;51:654-64.

160. Baker LD. Exercise and memory decline. Alzheimers Dement. 2016;12:P220-1.

161. Chen Y, Wang DJJ, Detre JA. Test-retest reliability of arterial spin labeling with common labeling strategies. J Magn Reson Imaging. 2011;33:940-9.

162. Wu B, Lou X, Wu X, Ma L. Intra- and interscanner reliability and reproducibility of 3D whole-brain pseudo-continuous arterial spin-labeling MR perfusion at 3T. J Magn Reson Imaging. 2014;39:402-9.

163. Mutsaerts HJMM, Steketee RME, Heijtel DFR, Kuijer JPA, van Osch MJP, Majoie CBLM, et al. Inter-vendor reproducibility of pseudo-continuous arterial spin labeling at 3 Tesla. PLoS One. 2014;9:e104108.

164. Alsop DC, Detre JA, Golay X, Günther M, Hendrikse J, Hernandez-Garcia L, et al. Recommended implementation of arterial spin-labeled perfusion MRI for clinical applications: a consensus of the ISMRM perfusion study group and the European consortium for ASL in dementia. Magn Reson Med. 2015;73: $102-16$.

165. Mutsaerts HJMM, van Osch MJP, Zelaya FO, Wang DJJ, Nordhøy W, Wang Y, et al. Multi-vendor reliability of arterial spin labeling perfusion MRI using a near-identical sequence: implications for multi-center studies. Neurolmage. 2015;113:143-52.

166. Biswal BB, Mennes M, Zuo X-N, Gohel S, Kelly C, Smith SM, et al. Toward discovery science of human brain function. PNAS. 2010;107:4734-9.

167. Zuo X-N, Anderson JS, Bellec P, Birn RM, Biswal BB, Blautzik J, et al. An open science resource for establishing reliability and reproducibility in functional connectomics. Sci Data. 2014;1:140049.

168. Jovicich J, Minati L, Marizzoni M, Marchitelli R, Sala-Llonch R, Bartrés-Faz D, et al. Longitudinal reproducibility of default-mode network connectivity in healthy elderly participants: a multicentric resting-state fMRI study. Neurolmage. 2016;124:442-54.

169. Marchitelli R, Minati L, Marizzoni M, Bosch B, Bartrés-Faz D, Müller BW, et al. Test-retest reliability of the default mode network in a multi-centric fMRI study of healthy elderly: effects of data-driven physiological noise correction techniques. Hum Brain Mapp. 2016;37:2114-32.

170. Lorenzi MM, Beltramello A, Mercuri NB, Canu E, Zoccatelli G, Pizzini FB, et al. Effect of memantine on resting state default mode network activity in Alzheimer's disease. Drugs Aging. 2012;28:205-17.

171. Solé-Padullés C, Bartrés-Faz D, Lladó A, Bosch B, Peña-Gómez C, Castellví M, et al. Donepezil treatment stabilizes functional connectivity during resting state and brain activity during memory encoding in Alzheimer's disease. J Clin Psychopharmacol. 2013;33:199-205.

172. Fox NC, Black RS, Gilman S, Rossor MN, Griffith SG, Jenkins L, et al. Effects of Abeta immunization (AN1792) on MRI measures of cerebral volume in Alzheimer disease. Neurology. 2005;64:1563-72.

173. Quinn JF, Raman R, Thomas RG, Yurko-Mauro K, Nelson EB, Van Dyck C, et al. Docosahexaenoic acid supplementation and cognitive decline in Alzheimer disease. JAMA. 2010;304:1903-11.

174. Wilkinson D, Fox NC, Barkhof F, Phul R, Lemming O, Scheltens P. Memantine and brain atrophy in Alzheimer's disease: a 1-year randomized controlled trial. J Alzheimers Dis. 2012;29:459-69.

175. McDonald CR, Gharapetian L, McEvoy LK, Fennema-Notestine C, Hagler DJ, Holland D, et al. Relationship between regional atrophy rates and cognitive decline in mild cognitive impairment. Neurobiol Aging. 2012;33:242-53.

176. Jovicich J, Czanner S, Han X, Salat D, van der Kouwe A, Quinn B, et al. MRIderived measurements of human subcortical, ventricular and intracrania brain volumes: reliability effects of scan sessions, acquisition sequences, data analyses, scanner upgrade, scanner vendors and field strengths. Neurolmage. 2009;46:177-92.

177. Wonderlick JS, Ziegler DA, Hosseini-Varnamkhasti P, Locascio JJ, Bakkour A, van der Kouwe A, et al. Reliability of MRI-derived cortical and subcortical morphometric measures: effects of pulse sequence, voxel geometry, and parallel imaging. Neurolmage. 2009;44:1324-33.

178. Cover KS, van Schijndel RA, Versteeg A, Leung KK, Mulder ER, Jong RA, et al. Reproducibility of hippocampal atrophy rates measured with manual, FreeSurfer, AdaBoost, FSL/FIRST and the MAPS-HBSI methods in Alzheimer's disease. Psychiatry Res. 2016;252:26-35.
179. Wolz R, Schwarz AJ, Yu P, Cole PE, Rueckert D, Jack CR Jr, et al. Robustness of automated hippocampal volumetry across magnetic resonance field strengths and repeat images. Alzheimers Dement. 2014;10:430-438.e2.

180. Frisoni GB, Jack CR Jr, Bocchetta M, Bauer C, Frederiksen KS, Liu Y, et al. The EADC-ADNI Harmonized Protocol for manual hippocampal segmentation on magnetic resonance: evidence of validity. Alzheimers Dement. 2015;11: $111-25$.

181. Haller S, Falkovskiy P, Meuli R, Thiran J-P, Krueger G, Lovblad K-O, et al. Basic MR sequence parameters systematically bias automated brain volume estimation. Neuroradiology. 2016;58:1153-60.

182. Andrews KA, Modat M, Macdonald KE, Yeatman T, Cardoso MJ, Leung KK, et al. Atrophy rates in asymptomatic amyloidosis: implications for Alzheimer prevention trials. PLoS One. 2013:8:e58816.

183. Fox NC, Ridgway GR, Schott JM. Algorithms, atrophy and Alzheimer's disease: cautionary tales for clinical trials. Neurolmage. 2011;57:15-8.

184. Teipel SJ, Ewers M, Wolf S, Jessen F, Kölsch H, Arlt S, et al. Multicentre variability of MRI-based medial temporal lobe volumetry in Alzheimer's disease. Psychiatry Res. 2010;182:244-50.

185. Zhu T, Hu R, Qiu X, Taylor M, Tso Y, Yiannoutsos C, et al. Quantification of accuracy and precision of multi-center DTI measurements: a diffusion phantom and human brain study. Neurolmage. 2011;56:1398-411.

186. Walker L, Curry M, Nayak A, Lange N, Pierpaoli C. the Brain Development Cooperative Group. A framework for the analysis of phantom data in multicenter diffusion tensor imaging studies. Hum Brain Mapp. 2013;34: 2439-54.

187. Brueggen K, Grothe MJ, Dyrba M, Fellgiebel A, Fischer F, Filippi M, et al. The European DTI Study on Dementia-a multicenter DTI and MRI study on Alzheimer's disease and mild cognitive impairment. Neurolmage. 2017;144: 305-8.

188. Kilimann I, Likitjaroen Y, Hampel H, Teipel S. Diffusion tensor imaging to determine effects of antidementive treatment on cerebral structural connectivity in Alzheimer's disease. Curr Pharm Des. 2013;19:6416-25.

189. Sperling RA, Jack CR, Black SE, Frosch MP, Greenberg SM, Hyman BT, et al. Amyloid-related imaging abnormalities in amyloid-modifying therapeutic trials: recommendations from the Alzheimer's Association Research Roundtable Workgroup. Alzheimers Dement. 2011;7:367-85.

190. Carlson C, Siemers E, Hake A, Case M, Hayduk R, Suhy J, et al. Amyloidrelated imaging abnormalities from trials of solanezumab for Alzheimer's disease. Alzheimers Dement. 2016;2:75-85.

191. Arrighi HM, Barakos J, Barkhof F, Tampieri D, Jack C, Melançon D, et al. Amyloid-related imaging abnormalities-haemosiderin (ARIA-H) in patients with Alzheimer's disease treated with bapineuzumab: a historical, prospective secondary analysis. J Neurol Neurosurg Psychiatr. 2016;87:106-12.

192. Barkhof F, Daams M, Scheltens P, Brashear HR, Arrighi HM, Bechten A, et al. An MRI rating scale for amyloid-related imaging abnormalities with edema or effusion. AJNR Am J Neuroradiol. 2013;34:1550-5.

193. Shams S, Wahlund L-O. Cerebral microbleeds as a biomarker in Alzheimer's disease? A review in the field. Biomark Med. 2016;10:9-18.

194. Yates PA, Desmond PM, Phal PM, Steward C, Szoeke C, Salvado O, et al. Incidence of cerebral microbleeds in preclinical Alzheimer disease. Neurology. 2014;82:1266-73.

195. Salloway S, Sperling R, Gilman S, Fox NC, Blennow K, Raskind M, et al. A phase 2 multiple ascending dose trial of bapineuzumab in mild to moderate Alzheimer disease. Neurology. 2009;73:2061-70.

196. Ritchie CW, Molinuevo JL, Truyen L, Satlin A, Van der Geyten S, Lovestone S, et al. Development of interventions for the secondary prevention of Alzheimer's dementia: the European Prevention of Alzheimer's Dementia (EPAD) project. Lancet Psychiatry. 2016;3:179-86.

197. Frost C, Kenward MG, Fox NC. Optimizing the design of clinical trials where the outcome is a rate. Can estimating a baseline rate in a run-in period increase efficiency? Stat Med. 2008;27:3717-31.

198. Ellis KA, Bush Al, Darby D, De Fazio D, Foster J, Hudson P, et al. The Australian Imaging, Biomarkers and Lifestyle (AIBL) study of aging: methodology and baseline characteristics of 1112 individuals recruited for a longitudinal study of Alzheimer's disease. Int Psychogeriatr. 2009;21:672-87.

199. Jack CR, Bernstein MA, Borowski BJ, Gunter JL, Fox NC, Thompson PM, et al. Update on the magnetic resonance imaging core of the Alzheimer's disease neuroimaging initiative. Alzheimers Dement. 2010;6:212-20.

200. Klunk WE, Engler H, Nordberg A, Wang Y, Blomqvist G, Holt DP, et al. Imaging brain amyloid in Alzheimer's disease with Pittsburgh Compound-B. Ann Neurol. 2004:55:306-19. 
201. Mathis CA, Mason NS, Lopresti BJ, Klunk WE. Development of positron emission tomography $\beta$-amyloid plaque imaging agents. Semin Nucl Med. 2012:42:423-32.

202. Schwarz AJ, Yu P, Miller BB, Shcherbinin S, Dickson J, Navitsky M, et al. Regional profiles of the candidate tau PET ligand 18F-AV-1451 recapitulate key features of Braak histopathological stages. Brain. 2016;139:1539-50.

203. Frisoni GB, Fox NC, Jack CR, Scheltens P, Thompson PM. The clinical use of structural MRI in Alzheimer disease. Nat Rev Neurol. 2010;6:67-77.

204. Weston PSJ, Simpson IJA, Ryan NS, Ourselin S, Fox NC. Diffusion imaging changes in grey matter in Alzheimer's disease: a potential marker of early neurodegeneration. Alzheimers Res Ther. 2015;7:47.

205. Bartlett JW, Frost C, Mattsson N, Skillbäck T, Blennow K, Zetterberg H, et al. Determining cut-points for Alzheimer's disease biomarkers: statistical issues, methods and challenges. Biomarkers Med. 2012;6:391-400.

206. Jack CR, Wiste HJ, Weigand SD, Therneau TM, Lowe VJ, Knopman DS, et al. Defining imaging biomarker cut points for brain aging and Alzheimer's disease. Alzheimers Dement. 2017:13:205-16.

207. Yaqub M, Tolboom N, Boellaard R, van Berckel BNM, van Tilburg EW, Luurtsema G, et al. Simplified parametric methods for [11C]PIB studies. Neurolmage. 2008:42:76-86.

Ready to submit your research? Choose BMC and benefit from:

- fast, convenient online submission

- thorough peer review by experienced researchers in your field

- rapid publication on acceptance

- support for research data, including large and complex data types

- gold Open Access which fosters wider collaboration and increased citations

- maximum visibility for your research: over $100 \mathrm{M}$ website views per year

At BMC, research is always in progress.

Learn more biomedcentral.com/submissions 